\title{
UN ZAIBATSU FUERA DE LUGAR: LOS ORÍGENES DEL GRUPO FIERRO (1870-1939) *
}

ELENA SAN ROMÁN

Universidad Complutense ${ }^{\text {a }}$

A Zaibatsu Out of Place: the Origins of the Fierro Group (1870-1939)

\begin{abstract}
This work focuses on the origins of the Fierro Group. Ildefonso Fierro (1882-1961) was one of the most prominent businessmen of Franco's regime. Fierro's case study presents two features that distinguish it from other Spanish family firms founded in the first half of the twentieth century: its high degree of diversification and its peculiar financial history. Prior to the commencement of the Franco dictatorship, Fierro had managed to form a diversified family business and had bought a bank to finance his industrial activity. This article analyzes how he achieved this and compares his path with that of the Japanese Zaibatsu.
\end{abstract}

Keywords: business history, family business, new firms, Grupo Fierro, zaibatsu

JEL Classification: L10, N84

* Received 06/09/2009. Accepted 10/01/2009. Este trabajo forma parte de una biografía, en curso, sobre Ildefonso Fierro. Agradezco a Alfonso y Juan Fierro March y a Marcelino Elosúa su generosidad y su colaboración. Agradezco también a los evaluadores anónimos sus observaciones minuciosas e inteligentes que han contribuido a mejorar notablemente el texto inicial. Mi agradecimiento a José Luis García Ruiz y José María Ortiz Villajos por su ayuda y a Antonio Gómez Mendoza, Enrique Llopis, Fernando García de la Noceda y Javier Fierro por sus correcciones y comentarios.

a Departamento de Historia e Instituciones Económicas II, Facultad de CCEE y EE., Campus de Somosaguas 28224 Pozuelo de Alarcón, sanro@ccee.ucm.es. 


\section{RESUMEN}

Este trabajo estudia los orígenes y formación del grupo de empresas de Ildefonso Fierro (1882-1961), uno de los empresarios más destacados en la España de Franco. El caso Fierro presenta dos características que lo alejan de otras empresas familiares españolas nacidas en la primera mitad del siglo xx: su alto nivel de diversificación y su peculiar historia financiera. Antes de que comenzara la dictadura de Franco, Fierro había logrado formar una empresa familiar diversificada y había comprado un banco para financiar su actividad industrial. En estas páginas se analiza cómo lo logró y se compara su trayectoria con la de los zaibatsu japoneses.

Palabras clave: historia empresarial, empresa familiar, creación de empresas, Grupo Fierro, zaibatsu

\section{INTRODUCCIÓN}

En el momento de su muerte, el 6 de diciembre de 1961, Ildefonso Fierro Ordóñez era uno de los empresarios más importantes e influyentes de España. Presidió su cortejo fúnebre el ministro subsecretario de la Presidencia, Luis Carrero Blanco, al que acompañaron en el sepelio otros seis ministros del Gobierno: los de Exteriores, Hacienda, Gobernación, Obras Públicas, Comercio y Ejército ${ }^{1}$. La magnitud de los negocios de Fierro explica una representación oficial, que no pasó inadvertida en la prensa nacional ni en la extranjera ${ }^{2}$. El fallecido era fundador y presidente del Banco Ibérico, que se contaba entre los doce bancos privados españoles más importantes ${ }^{3}$. Poseía, además, otra treintena de sociedades en España y unas quince en el extranjero, repartidas por América central y latina y por el norte de África.

¿Cómo había logrado este imperio? No fue, desde luego, gracias a sus orígenes familiares, ni tampoco a una formación esmerada que le hubiera facilitado cierta excelencia profesional. Fierro pertenecía a una sencilla familia de la montaña leonesa y, por todo estudio, cursó unos años en una escuela de Comercio de provincias. Sin embargo, tenía inteligencia natural y lo que coloquialmente se define como "olfato» para los negocios. Su biografía transluce el "espíritu de empresa» que no faltó en la España del siglo $\mathrm{xx}^{4}$ : Fierro fue un hombre audaz y emprendedor que supo establecer útiles relaciones personales y cultivarlas.

\footnotetext{
1 Eran, respectivamente, Fernando María Castiella, Mariano Navarro Rubio, Camilo Alonso Vega, Jorge Vigón, Alberto Ullastres y Antonio Barroso. Diario ABC, 8-12-1961.

2 Apareció la noticia de su fallecimiento en el New York Journal el 7 de diciembre y en The Times el 8 de diciembre. Archivo Fierro, R. 392.

3 Era el undécimo de los bancos privados por activos netos según la clasificación de Carreras y Tafunell (1993, p. 165).

4 Tortella (2000, p. 15).
} 
Estas páginas analizan la formación del grupo de empresas de Ildefonso Fierro. Cronológicamente me detendré al final de la guerra civil. Para entonces, el empresario leonés, a punto de cumplir sesenta años, tenía ya conformado el núcleo central de sus negocios y había desarrollado un modelo de crecimiento y de gestión que no varió en adelante. Desde 1939 hasta su muerte, el grupo continuó su expansión y, sobre todo, vivió un proceso de internacionalización que será objeto de otro trabajo. Éste se centra en el tipo de empresa familiar que fundó Fierro. Dos de sus características revelan que los negocios del leonés fueron algo distintos a los de otras empresas familiares de la época: me refiero a su grado de diversificación y a su peculiar historia financiera.

Las empresas familiares españolas han tendido, con cierta frecuencia, a la especialización sectorial. No es difícil, por ello, asociar apellidos con actividades: los Aznar con el negocio naviero, los Entrecanales con la construcción, los Luca de Tena con información, los Puig con perfumería y los Mahou, Raventós y Osborne con el sector agroalimentario, por citar algunos ejemplos cercanos temporalmente al de Fierro ${ }^{5}$. Aunque haya quienes asocien igualmente el apellido Fierro con los fósforos, el grado de diversificación de sus actividades fue superior al de otras empresas que incluyen a las que he citado ${ }^{6}$. En 1939 Ildefonso Fierro estaba firmemente asentado en cinco líneas de negocio diferentes: fósforos, minería, transporte marítimo, finanzas y construcción. Pero tenía, además, un variopinto grupo de sociedades que abarcaban, desde los seguros o los perfumes, hasta la fabricación de accesorios para aviones. Con el tiempo, esta tendencia a la diversificación se acentuó. En 1961, junto a las cinco líneas de negocios indicadas, Fierro poseía sociedades inmobiliarias, otras de artes gráficas como SUTNAI y Rieusset, que eran las dos empresas concesionarias de la impresión del Documento Nacional de Identidad, empresas metalúrgicas como Almuso y Mequinsa y otras de manufacturas metálicas como COINTRA. El empresario leonés controlaba FASA Renault y acababa de crear una empresa petrolera, PETROLIBER, que proyectaba una refinería en Galicia.

Los negocios financieros de Fierro, segunda característica, aún lo alejan más del resto de las empresas familiares españolas de su tiempo, puesto que no ha habido muchos empresarios que hayan creado un banco como consecuencia de una actividad industrial previa. El proceso ha sido más frecuentemente el contrario: la Banca antecediendo a la industria o, al menos, desarrollándose a la par. Hay en España familias propietarias de bancos, como los Urquijo, los Herrero o los Botín, cuya capacidad financiera impulsó actividades diversas y generó carteras industriales de importancia. En muchos casos comenzaron

5 Las biografías de José Entrecanales Ibarra (1899-1990), Torcuato Luca de Tena y ÁlvarezOssorio (1861-1929), Antóni Puig i Castelló (1889-1979), Casimiro Mahou García (1881-1943), Manuel Raventós y Doménech (1862-1930) y Roberto Osborne Guezala (1871-1937) se recogen en el libro de Torres (2000). Sobre los Aznar existe la monografía de Valdaliso (2006), sobre Mahou la de García Ruiz (1999) y sobre Puig puede verse el trabajo de Puig Raposo (2003).

6 Prueba de ello es que en las notas necrológicas publicada por The Times y por el New York Journal mencionaban multitud de actividades de Fierro, pero no los fósforos. 
como casas de banca y comercio que derivaron, con el tiempo, en las grandes entidades financieras que conocemos ${ }^{7}$. Sin embargo Fierro lo hizo al revés: primero creó las empresas y después compró un Banco para financiarlas. De hecho, a él le gustaba definirse como empresario y no como banquero.

¿Fue entonces la de Fierro una empresa familiar atípica? Quizá su forma de entender los negocios resulta algo distinta a la de otras familias empresarias españolas de la época con las que, sin embargo y como es lógico, comparte importantes aspectos. Uno de los más significativos es, precisamente, la capacidad de aprovechar las oportunidades que ofrecieron las grandes coyunturas bélicas que afectaron a Europa a finales del siglo XIX y hasta la II Guerra Mundial para crear o hacer crecer sus negocios, como les pasó a los Aznar, los Ybarra, los Rivière, los Moreda o los Unceta, por citar algunos ejemplos ${ }^{8}$.

Por otra parte, los negocios de Ildefonso Fierro y su manera de enfocarlos no resulta tan singular si se le compara con lo sucedido fuera de nuestras fronteras. En primer lugar, el caso Fierro resulta paralelo al de otras familias empresarias europeas de orígenes modestos que también se expandieron con la venta de mineral o de metal durante las guerras que afectaron al viejo continente en el siglo pasado. Los beneficios obtenidos de los conflictos les permitieron diversificarse, contando, en algunos casos, con una base bancaria propia. Así sucedió, por ejemplo, con las tres familias empresarias descritas por James (2006): los Wendel, en Francia; los Haniel, en Alemania, y los Falk, en Italia.

Existe, además, un segundo plano de comparación posible aunque más lejano. Me refiero al caso japonés. En Japón, la empresa familiar diversificada o zaibatsu jugó un papel esencial en el crecimiento económico del país desde su formación, a raíz de la revolución Meiji, hasta su disolución tras la Segunda Guerra Mundial. La importancia de esta institución se ha traducido en una abundante literatura, repleta no sólo de monografías sobre zaibat$s u$ concretos, sino de excelentes visiones de conjunto, aún poco frecuentes para España, que me servirán de referencia a la hora de analizar el caso Fierro $^{9}$. El propio James (2003, p. 2) sugiere que sería posible encontrar

7 Sobre estos bancos existen excelentes monografías de Puig y Torres (2008), Anes y Otazu (1987) y Martín Aceña (2007), respectivamente.

8 En el caso de los Ybarra y de los Aznar puede verse el engrosamiento del patrimonio familiar alcanzado hacia 1930 y relacionado con los beneficios de la Gran Guerra que analizan Díaz Morlán (2002, pp. 156-160) y Valdaliso (2006, pp. 65-71). Sobre los Moreda y los Rivière también se recoge este aspecto en la monografía de Fernández Pérez (2004). Goñi (2009) explica la importancia de las coyunturas bélicas para el desarrollo de Esperanza y Unceta.

9 La empresa familiar ha recibido mucha atención en los últimos años. A ello han contribuido especialmente los trabajos de las profesoras Fernández Pérez y Puig Raposo. Ellas han sido las primeras en aportar visiones de conjunto sobre aspectos como la internacionalización, profesionalización o longevidad de las empresas familiares en perspectiva histórica, apoyándose en sus propias monografías y en el resto de las que, en los últimos años, se han publicado. N. Puig Raposo y P. Fernández Pérez (2007, 2009, 2009a), P. Fernández Pérez y N. Puig Raposo (2008), Fernández Pérez (2003, 2005 y 2006) y Puig Raposo (2003). Otra visión de conjunto sobre un aspecto clave, el de la sucesión, se ofrece en Díaz Morlán (2009, pp. 101-110). 
modelos de empresa familiar con muchos aspectos comunes a las europeas entre las de Japón, China o India.

La coincidencia cronológica entre los zaibatsu y la formación de los negocios de Fierro y la inexistencia de comparaciones en este sentido me han hecho inclinarme por el país asiático para elegir un término exterior de comparación.

He dividido mi trabajo en cinco apartados. Los tres primeros repasan el nacimiento de las empresas de Fierro. En el cuarto analizo el estado de sus negocios a la altura de 1939 y, por último, el quinto ofrece algunas reflexiones a la vista de la experiencia japonesa.

\section{DE ARRIEROS LEONESES A COMERCIANTES ASTURIANOS: FIERRO HERMANOS Y T. FIERRO E HIJOS}

Ildefonso Fierro Ordóñez nació el 23 de enero de 1882 en Lugueros, una pequeña población de la comarca leonesa de los Argüellos que limita con Asturias. Desde el siglo XVII, muchos argollanos habían compaginado las tareas del campo con la arriería. Los arrieros argollanos se habían especializado en el transporte de pescado asturiano hacia León a través del Puerto de Vegarada. A diferencia de los arrieros de otras zonas, los argollanos no se limitaban al transporte de la mercancía, sino que solían negociarla. Tenían un marcado espíritu comercial, propio de las personas obligadas a tomar decisiones y a arriesgarse en las operaciones de compra venta ${ }^{10}$.

Como muchos de sus paisanos, el padre de Ildefonso Fierro, Toribio González-Fierro, también fue un hombre emprendedor ${ }^{11}$. Hacia 1870 se asoció con su hermano Félix para crear la empresa Fierro Hermanos, cuya base de operaciones estaba en suelo asturiano, concretamente en San Esteban de Pravia. Originariamente Fierro Hermanos se dedicó a la compraventa de pescado, carbón y madera. A estas actividades añadieron la exportación de carbones desde el Puerto de San Esteban, convirtiéndose en consignatarios de buques y agentes de aduanas. En el vecino municipio de La Arena instalaron, además, una fábrica de conservas de pescado.

La sociedad Fierro Hermanos duró hasta 1907. En aquel año, Félix y Toribio decidieron, de común acuerdo, dividir sus negocios en dos lotes y separarse. Félix se quedó con los negocios «de tierra», la fábrica de conservas, y Toribio con los «de mar», la consignación de buques y la venta de mercancías por vía marítima. Una vez desaparecido Fierro Hermanos,

10 Cubillo (2006, pp. 82-94).

11 El apellido originario de Ildefonso Fierro es González Fierro. El «González Fierro» de su padre no era compuesto aunque lo había sido durante siglos. Ildefonso Fierro unió González-Fierro en 1924 para recuperar el compuesto y en 1947 suprimió el González. Utilizaré sólo el apellido Fierro, por el que fue conocido. Sobre el cambio de apellido véase Archivo Fierro R. 394. Sobre Fierro véase también la biografía de García Ruiz (2000). 
Toribio creó una nueva sociedad, T. Fierro e Hijos, que fue escriturada el 16 de junio de 1908 como sociedad regular colectiva en San Esteban de Pravia ${ }^{12}$. Los socios iniciales fueron Toribio y sus dos hijos mayores, Valentín e Ildefonso, y a ellos se unieron con el tiempo los otros hermanos varones, Federico, Félix y José ${ }^{13}$.

Ildefonso comenzó a trabajar con su padre nada más cumplir dieciocho años. Hasta los catorce había vivido en Lugueros. Los cuatro siguientes los pasó en Avilés, estudiando comercio y haciendo prácticas en la casa Sucesores de Espinosa ${ }^{14}$. Cuando se incorporó a la empresa familiar, Ildefonso se hizo cargo de los negocios marítimos, mientras que su hermano mayor, Valentín, dirigía una fábrica de conservas adquirida en el propio San Esteban.

En 1910 la sociedad T. Fierro e Hijos dio un importante paso al comprar, por iniciativa de Ildefonso, su primer barco, el «Mieres», que naufragó en agosto de 1911. El «Mieres» fue sustituido por el «Fierros», un vapor de 1.200 TRB que permitió a los Fierro aprovechar la favorable coyuntura de la huelga portuaria de Londres en 1912. En febrero de 1913 Ildefonso compró a los armadores Wilson \& Reid de Belfast, Irlanda, el vapor «Carlisle», de 1.400 TRB, al que cambió el nombre por el de «Alfonso Fierro». Este vapor se perdió a la altura de la Estaca de Vares en diciembre de 1919 pero, junto al vapor Fierros, otorgó numerosos beneficios a la familia antes de su desaparición.

\section{LOS BENEFICIOS DE LA GRAN GUERRA}

Tras unos comienzos no exentos de dificultades, la Primera Guerra Mundial proporcionó a los Fierro su primer gran salto adelante. Eran tiempos de carbón y transportes caros y escasos, y por ello, ambos sectores vivieron una formidable bonanza. Como reconocía la prensa, Asturias se había convertido en un nuevo Eldorado, y el carbón, en oro negro ${ }^{15}$. El crecimiento del negocio se tradujo, para Ildefonso, en numerosos viajes buscando oportunidades de transportar mercancías. Los resultados fueron positivos para la empresa familiar: el recuento de valores industriales y fondos públicos con que contaba T. Fierro e Hijos (cuadro 1) era ya notable en 1916 si se considera que la familia había partido de un patrimonio minúsculo ${ }^{16}$.

12 Se recoge la referencia notarial en la escritura de constitución de la Sociedad Comercial Asturiana. Archivo Fierro, R. 359.

13 Ildefonso Fierro era el segundo de diez hermanos. Su padre, Toribio González Fierro, casó en primeras nupcias con Gregoria Rodríguez González y tuvo un hijo al que llamó Valentín. Enviudó en 1878 y volvió a casar en 1881 con Genoveva Ordóñez Fernández, que le dio otros nueve hijos.

14 En Avilés estudió tres años en la Academia La Merced, dirigida por Domingo Álvarez de Acebal (1846-1924), pedagogo y matemático de renombre. «Apuntes para una biografía de Ildefonso González Fierro escritos por Félix González Fierro», Archivo Fierro, R. 393.

15 Aguirre de Viar (1918, p. 102).

16 «Carta adjuntando relación de valores industriales y fondos públicos»16-5-1916, Archivo Fierro, R. 200. 
Como se observa en el cuadro 1, Toribio Fierro e Hijos tenía una política de inversiones bastante conservadora: apostaba por la seguridad de los fondos públicos y se concentraba en empresas relacionadas con un sector bien conocido para ellos como era el del transporte marítimo, o en valores consolidados como los ferrocarriles o el Banco Hipotecario. Completaban su cartera las acciones de General Azucarera de España, sin duda la más importante, grande y sólida de su sector por aquellos años.

Si traducimos el valor total que tenían las acciones de T. Fierro e Hijos, 1,6 millones de pesetas de 1916, a euros del 2009 la cifra superaría los cinco millones ${ }^{17}$. Otro ejercicio de comparación ayudará a comprender la magnitud de este dinero: en 1916 cotizaban en la Bolsa de Madrid un total de 47 bancos. Pues bien, casi un 30 por cien de ellos tenían un capital inferior al que los Fierro habían invertido en valores industriales y fondos públicos. El 25 por cien de las empresas de agua, gas y electricidad que cotizaban en la bolsa y de las navieras y de construcción naval tampoco alcanzaba esa cifra ${ }^{18}$. Siendo sustanciosa la cuantía de la cartera de valores de los Fierro, es preciso tener en cuenta que no representa más que una parte de lo ganado en la guerra, puesto que otra parte importante fue reinvertida. Efectivamente, en aquellos años la empresa familiar aumentó su flota y adquirió minas de Carbón en Mieres, Villablino y Cangas de Narcea. Ildefonso Fierro compró también, a título personal, unas minas de baritina en San Martín de Luiña e instaló en Soto del Barco una fábrica para su molienda y venta ${ }^{19}$. Al lado del puerto de San Esteban estaban otros dos de sus negocios: la fábrica de briquetas y la de conservas, que vendía a toda España e incluso exportaba algunos de sus productos. A raíz de la Gran Guerra, Toribio Fierro e Hijos se había transformado en una notable sociedad que se movía ya fuera de suelo asturiano y destacaba como consignataria de buques, agente de aduanas, exportadora de carbones, almacenista al por mayor de coloniales y agente de seguros, entre otras actividades. Aunque desconozco el patrimonio exacto de Fierro justo antes de comenzar la Primera Guerra Mundial, es innegable que las circunstancias de la guerra le facilitaron una expansión de sus negocios: fue entonces, y no antes, cuando Ildefonso Fierro compró minas y amplió su flota y cuando adquirió una península cercana a la Arena, en Soto del Barco, donde se ubicaba el Castillo de San Martín, una antigua fortaleza medieval. En aquel paraje el joven Fierro se construyó una magnífica casa que constituía todo un símbolo de los éxitos cosechados.

El crecimiento de los negocios aconsejaba la creación de nuevas sociedades especializadas. En 1919 se separaron, por segunda vez en la historia de la familia, los negocios de tierra y los de mar. El 1 de agosto se creó la

17 He usado las series de PIB de Prados (2003), empalmándolas en 1958. La tasa de inflación de los últimos años es la que ofrece el INE.

18 Anuario Estadístico de España de 1916, pp. 192-198.

19 «Escritura de constitución de la Sociedad Comercial Asturiana». Archivo Fierro, R. 359. 


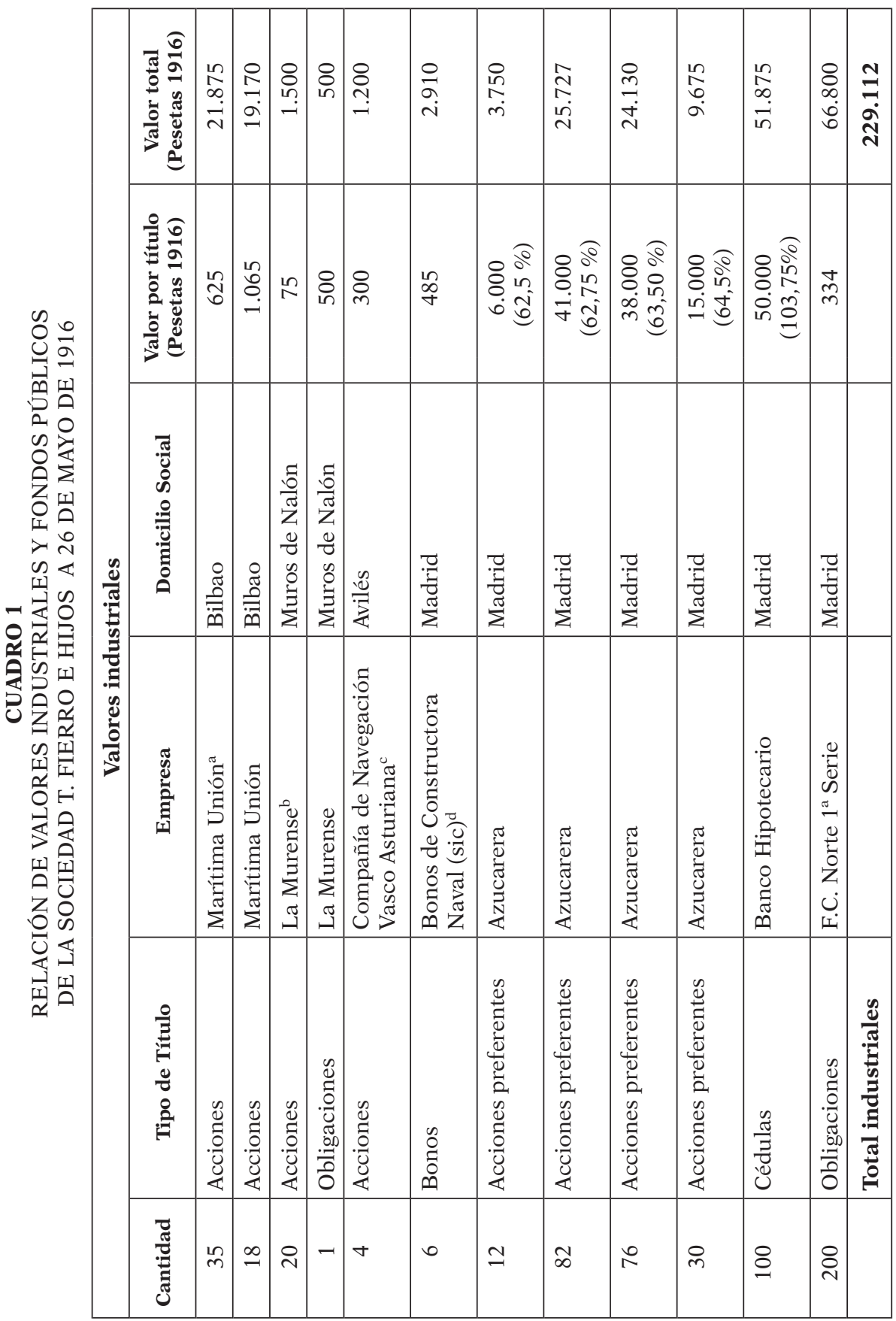




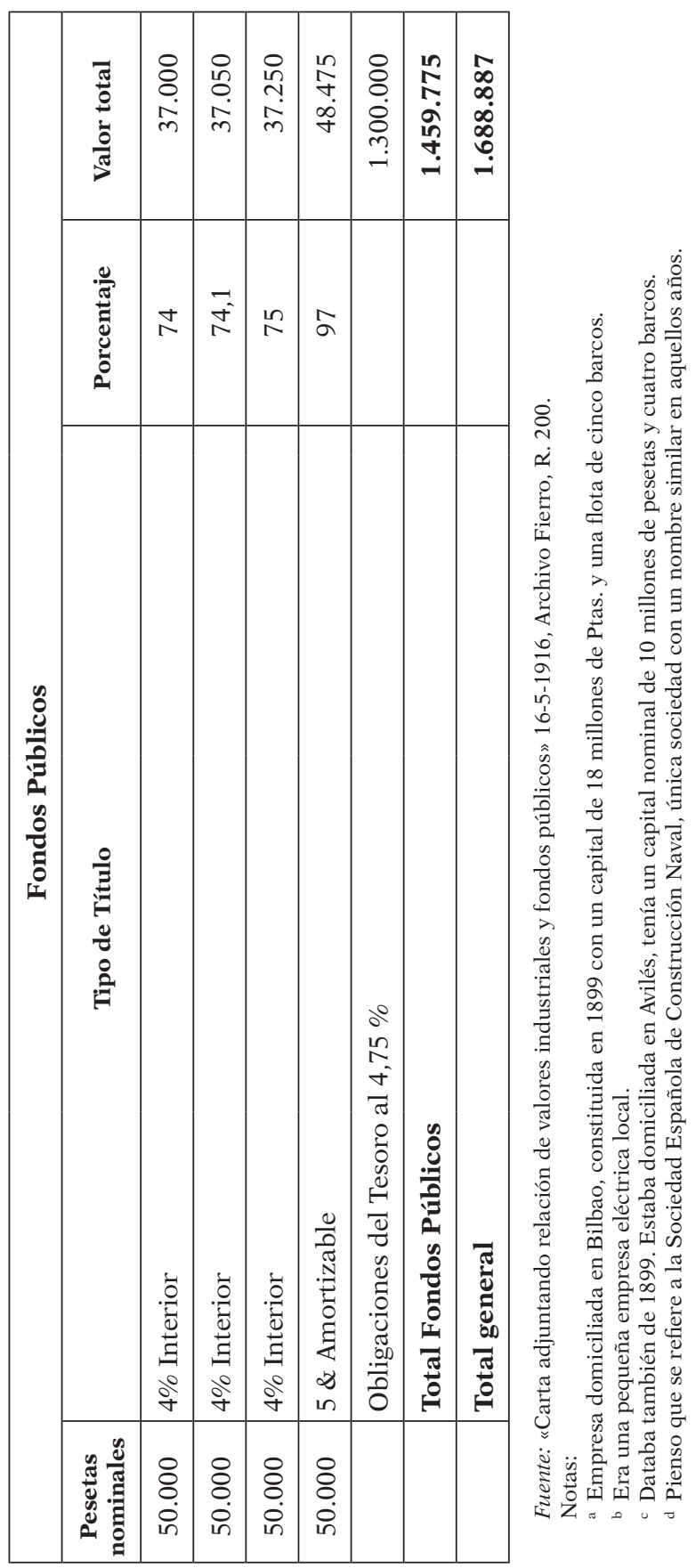


Naviera Fierros para gestionar barcos y fletes. El recién fundado Banco Urquijo ayudó en la creación de esta iniciativa, en la que Ildefonso fue nombrado director gerente y su hermano Félix, consejero delegado ${ }^{20}$. En febrero de 1920 nació la empresa que aunaba las actividades de tierra: la Sociedad Comercial Asturiana. A ella se vincularon las minas de Mieres, Cangas de Tineo y Villablino, las fábricas de baritina y briqueta de San Esteban de Pravia y algunas edificaciones en Oviedo. En la constitución de esta sociedad colaboraron, por una parte, Toribio Fierro e Hijos y, por otra, Ildefonso, que aportó las minas de baritina y la fábrica adquiridas a título personal durante la guerra. Las acciones de la empresa se repartieron entre los miembros de la familia, pero Ildefonso tenía más del 50 por cien y, por ello, la capacidad para dirigir y decidir sobre la nueva sociedad. La Comercial Asturiana, futura Financiera Fierro, se convirtió en una empresa muy versátil, intermediaria entre las diversas sociedades del empresario leonés. Las dos nuevas sociedades se domiciliaron en Oviedo, a donde Fierro se trasladó al terminar la Primera Guerra Mundial. En Oviedo entabló gran amistad con la familia Herrero, propietaria del Banco del mismo nombre. Esa amistad, especialmente estrecha con Ignacio Herrero, marqués de Aledo, les llevó a colaborar en muchos negocios y facilitó la entrada de Ildefonso Fierro en el mundo financiero y empresarial madrileño ${ }^{21}$.

La creación de la Naviera Fierros y de la Sociedad Comercial Asturiana supuso la práctica desaparición de Toribio Fierro e Hijos. Con una buena parte de sus activos traspasados a las nuevas empresas, sólo quedaron en manos de la vieja empresa familiar algunos negocios menores de San Esteban de Pravia. En diciembre de 1920 Ildefonso Fierro se separó, con su hermano Félix, de Toribio Fierro e Hijos, que siguió constituida por su padre y sus hermanos Federico y José. Sin embargo, la continuación del negocio carecía ya de sentido y en marzo de 1922 se extinguió la empresa de Toribio.

\section{MADRID Y LA EXPANSIÓN}

Los mismos sectores que facilitaron el negocio de Fierro durante la Gran Guerra, carbón y transporte marítimo, fueron protagonistas de la crisis que empezó tras la llegada de la paz y que tocó fondo en 1921. Las escasas posibilidades de crecer si continuaba vinculado a Asturias, al carbón y a los fletes,

20 Desconozco cómo se produjo el contacto entre el Banco Urquijo e Ildefonso Fierro. La Naviera Fierros no figura como empresa participada del Banco Urquijo en la lista de 350 sociedades participadas que han elaborado Nuria Puig y Eugenio Torres. En el trabajo colectivo Asturias y la Mar (Oviedo, 2006, p. 632), se dice que la Naviera Fierros se creó con el concurso del Banco Urquijo. También lo afirma Félix González Fierro, hermano de D. Ildefonso en «Apuntes para una biografía de Ildefonso González Fierro escritos por Félix González Fierro», Archivo Fierro, R. 393.

21 Datos facilitados por D. Martín González del Valle, Barón de Grado, en entrevista concedida el 4 de junio de 2008. 
hicieron que Fierro decidiera trasladarse a Madrid para abrir nuevas vías de negocio. La Sociedad Comercial Asturiana y la Naviera Fierros continuaron domiciliadas en Oviedo, pero Ildefonso delegó parte de sus responsabilidades en su hermano Félix. A Madrid le acompañaron tres de sus colaboradores asturianos de los tiempos de San Esteban de Pravia que se convirtieron, con el paso de los años, en personas de su máxima confianza: Luis Martínez Sánchez, de Soto del Barco; José Alonso Roza, natural de Colunga, que fue el responsable de la administración de las empresas del grupo Fierro, y, por último, Félix Monzón, un empleado del ferrocarril vasco asturiano que se convirtió en una suerte de secretario personal de Ildefonso ${ }^{22}$.

\subsection{La especialización: los fósforos}

La primera empresa madrileña de Fierro fue la Sociedad Ibérica de Contratación y Publicidad. Esta pequeña sociedad nació en 1921 para suministrar al monopolio de fabricantes de cerillas de España, con carácter de exclusividad, el cartón que se empleaba para fabricar las cajas de cerillas. Tenía, además, el derecho de insertar anuncios en estos envases.

Las relaciones que Ildefonso Fierro entabló con los fabricantes de cerillas a través de la Sociedad Ibérica de Contratación y Publicidad, y la ayuda de Ignacio Herrero, le permitieron aglutinar esfuerzos para ganar, en 1922, el concurso de arriendo del monopolio de los fósforos en España. Fierro se presentó al concurso junto a la Unión Fosforera de España, con la que se fusionó para formar la Compañía Arrendataria de Fósforos ${ }^{23}$. Desde la creación de la Arrendataria, Ildefonso perteneció a su Consejo de Administración y jugó un destacado papel como vicepresidente de la Sociedad y presidente del Comité de Gerencia. En el Consejo de Administración de la Arrendataria estaban dos personas clave para los negocios de Fierro: el ya citado Ignacio Herrero y Juan Navarro Reverter Gomis. Este último era hijo del político del mismo nombre que había sido ministro de Hacienda en la Restauración. Al igual que su padre, Juan Navarro Reverter se dedicó a la política, fue diputado del partido liberal y, sobre todo, a los negocios. Llegó a convertirse en un personaje muy conocido del mundo empresarial valenciano. Falleció en 1933, pero sus hijos continuaron una relación de amistad con Fierro, que se tradujo en numerosos negocios comunes.

Con el paso de los años, la familia Fierro fue ganando peso en el accionariado de la Arrendataria de Fósforos hasta hacerse con el control de la sociedad. Los fósforos se convirtieron en el centro de la expansión industrial del empresario leonés y protagonizaron la creación de otras dos empresas

22 «Notas sobre D. Ildefonso Fierro redactadas por D. José Jardón», Archivo Fierro, R. 471.

23 Real decreto adjudicando a las Sociedades «Unión Fosforera Española» e «Ibérica de Contratación y Publicidad» el servicio de fabricación de cerillas y fósforos. BOE 10/11/1922, núm. 314. 
en España, una tercera en Portugal y otra más en los territorios del protectorado español en Marruecos. Me refiero a la Compañía Industrial Expendedora, Fosforera Canariense, Fosforeira Portuguesa y Fosforera Marroquí.

La Compañía Industrial Expendedora nació en 1926, con 2,5 millones de pesetas de capital, como continuadora de la antigua Compañía Ibérica de Contratación y Publicidad ${ }^{24}$. Se trataba de un nuevo monopolio concesionario de los servicios de transporte, custodia, investigación y venta de toda clase de cerillas y fósforos, piedras de ignición y demás efectos del monopolio. Por su parte, la otra empresa española de fósforos, la Canariense, se creó en 1935 tras la compra de una fábrica de cerillas llamada El Crédito, que estaba en las Palmas de Gran Canaria.

La primera incursión de la familia Fierro en el mercado internacional se realizó a través de la Fosforeira Portuguesa, fundada en 1925 con un capital de cuatro millones de escudos, que al cambio eran 1,3 millones de pesetas de entonces ${ }^{25}$. Para esta aventura Ildefonso Fierro contó con algunos de los socios que le habían acompañado en España: de nuevo estaba presente la familia Navarro Reverter, la familia Herrero y su hermano Félix, entre otros. Aunque la sede de Fosforeira estaba en Lisboa, la Sociedad instaló su fábrica en Espinho, $18 \mathrm{~km}$ al sur de Oporto.

La última de las empresas fosforeras creada por Fierro antes de 1939 fue la Fosforera Marroquí, que se constituyó en Tetuán, en 1937, aprovechando el cierre de la frontera con el protectorado francés, la escasez de divisas que impedía la adquisición de importaciones en el régimen de libre comercio que había existido hasta entonces y el impulso de la política dirigista y autárquica que había comenzado a imponerse de la mano del Alto Comisario del protectorado, Juan Beigbeder ${ }^{26}$. En el marco de esta industrialización protegida nació Fosforera Marroquí, que al año de su creación, triplicó su capital y que, en 1939, colocó en el mercado unas 120.000 cajetillas de cerillas gruesas de las que sólo la mitad se quedaron en el Protectorado y el resto se exportaron a Tánger ${ }^{27}$.

\subsection{La diversificación}

El predominio de los fósforos no impidió la temprana diversificación del negocio industrial de Fierro. El empresario leonés continuó y expandió, por una parte, sus actividades más antiguas: la minería y el transporte maríti-

${ }^{24}$ Anuario Financiero de Bilbao que comprende el historial de valores públicos y de sociedades anónimas de España (Banco de Vizcaya, 1936, p. 1197).

25 «La casa Fierro y sus relaciones con la industria española», 1931, Archivo Fierro, R. 6. Para el tipo de cambio Martín Aceña y Pons (2005, p. 705).

26 Albert Salueña (2007, pp. 9-10).

27 «Boletín Oficial de la Zona de Protectorado Español en Marruecos, anexo al núm. 36, Registro Mercantil», p. 913. Archivo Fierro, R. 189. 
mo. Además, sumó otras dos nuevas líneas de negocio: construcción y banca. Y, por último, compró un grupo variopinto de sociedades. La descripción de sus negocios no quedaría completa si no añadiera, para terminar, unas líneas sobre las sociedades de las que fue consejero sin ser propietario.

Con respecto a la minería, la recuperación del mercado de carbones a partir de 1922 permitió a Fierro ampliar las actividades extractivas de la Sociedad Comercial Asturiana, que se habían frenado al terminar la Primera Guerra Mundial. En 1923, a la vista de que existía de nuevo alguna demanda y de que los precios eran algo más favorables, el Consejo de Administración decidió reanudar la explotación de las minas que poseía en Asturias. La recuperación minera alentó, además, la creación y compra de otras empresas del sector, de modo que, a finales de los años veinte, Fierro había consolidado un grupo de pequeñas sociedades mineras, que se recogen en el cuadro 2.

CUADRO 2

NEGOCIOS MINEROS DE FIERRO A FINALES DE LOS AÑOS VEINTE

\begin{tabular}{|l|c|c|c|}
\hline \multicolumn{1}{|c|}{$\begin{array}{c}\text { Nombre } \\
\text { de la empresa }\end{array}$} & $\begin{array}{c}\text { Año de } \\
\text { Constitución } \\
\text { de la empresa }\end{array}$ & $\begin{array}{c}\text { Año de } \\
\text { compra } \\
\text { por Fierro }\end{array}$ & $\begin{array}{c}\text { Capital nominal } \\
\text { y desembolsado } \\
\text { (Millones ptas. } \\
\text { corrientes) }\end{array}$ \\
\hline Comercial Asturiana & 1920 & - & 3 \\
\hline Española de Grafitos Refinados & 1924 & - & 2 \\
\hline Minera Manchego Asturiana & 1921 & 1925 & 2 \\
\hline Minas de Hierro del Narcea & 1909 & $1928 / 9$ & 1 \\
\hline Minera de Linares & 1918 & $1928 / 9$ & 7,038 \\
\hline
\end{tabular}

Fuente: Anuario Financiero y de Sociedades Anónimas de España (1930).

El desembarco de Fierro en la construcción se produjo en 1928, cuando, aprovechando las numerosas obras públicas emprendidas por la Dictadura de Primo de Rivera, Ildefonso Fierro ganó el concurso de construcción de los cargaderos de carbón y las obras del Puerto de San Esteban de Pravia, así como las del ferrocarril de Alicante a Alcoy. Para llevarlas a cabo constituyó la Constructora Fierro y para asegurarse el buen curso de la constructora compró la Compañía Anglo-Española de Cemento Portland El León, que tenía una fábrica en Matilla, Guadalajara ${ }^{28}$. Tanto en la constructora como en la cementera le acompañaron sus socios habituales: los Herrero,

28 Anuario Oficial de Valores de la Bolsa de Madrid, 1935, p. 67. Banco de España, Archivo Histórico, Operaciones, Leg. 296, expediente 774. Sobre la empresa véase López Calle (2004). 
los Navarro Reverter y sus hermanos. También le acompañaron los Navarro Reverter en la creación de la Compañía Ibérica de Construcciones Urbanas, S. A., una pequeña constructora que nació en 1931 y suspendió su actuación en $1936^{29}$.

La dimensión que adquirieron en los años veinte los negocios industriales de Fierro no se explicaría sin un soporte bancario. La aventura bancaria más importante de Ildefonso Fierro en la etapa que nos ocupa se la facilitó Juan Navarro Reverter: fue la compra del Banco Internacional de Comercio e Industria en asociación con el Banco de Valencia. El Banco Internacional de Industria y Comercio había nacido en 1924 y era una iniciativa con fuerte participación de la Société Générale de Belgique. La crisis de 1929 se hizo sentir en el banco de manera significativa y se tradujo en una clara reducción de los beneficios (véase gráfico 1).

\section{GRÁFICO 1}

BANCO INTERNACIONAL DE COMERCIO E INDUSTRIA. BENEFICIO LÍQUIDO 1924-1935 (en ptas. corrientes)

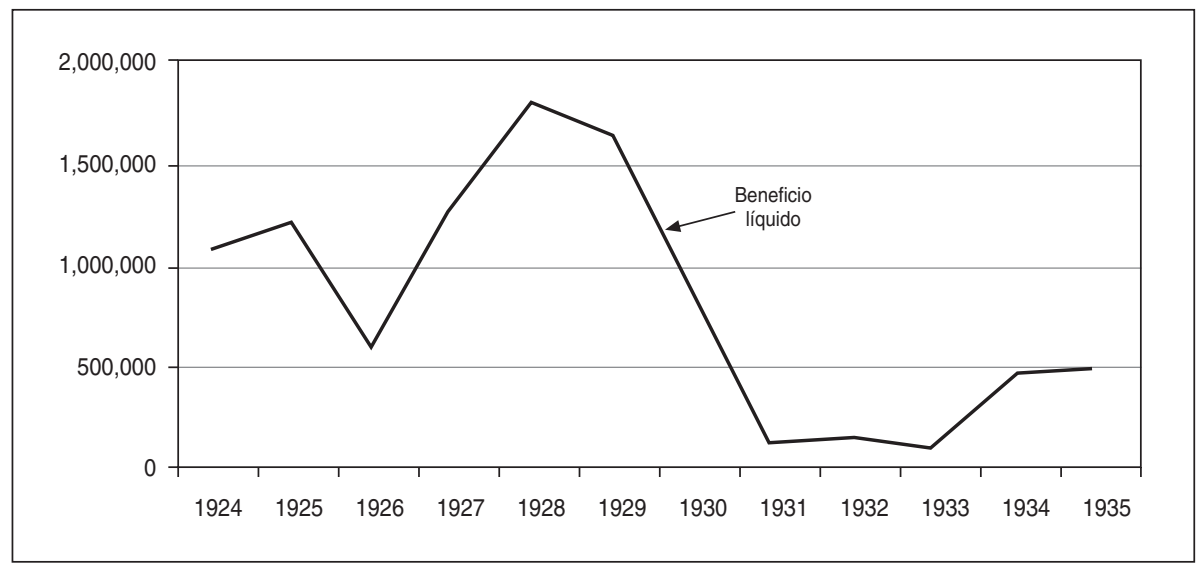

Fuente: Anuario Financiero de Bilbao (1936-1937).

En 1932, Fierro y el Banco de Valencia compraron todas las acciones que los belgas poseían en el Banco Internacional de Comercio e Industria. En concreto, Fierro adquirió 4.187 acciones a título personal, lo cual le convirtió en propietario de un 13,9 por cien del capital desembolsado del Banco y en consejero de la entidad ${ }^{30}$. Tras la adquisición del Banco, Juan Navarro Reverter fue nombrado presidente y Vicente Noguera, el presidente del Banco de Valencia, ocupó la Vicepresidencia. En 1933, el fallecimiento de Juan

29 Anuario Financiero y de Sociedades Anónimas de España (1935).

30 Banco de España, Archivo Histórico, Operaciones, Leg. 297, expediente 285. 
Navarro Reverter convirtió a Fierro en vicepresidente del Banco Internacional de Comercio e Industria. La relación entre Fierro y el Banco de Valencia quedó sellada en 1934, cuando el empresario leonés pasó a formar parte del Consejo de Administración de este Banco ${ }^{31}$. La operación de compra del Banco Internacional de Comercio e Industria había convertido a Ildefonso Fierro en copropietario de una entidad que, justo antes de la guerra civil, ocupaba el décimo tercer lugar entre los bancos españolas por el volumen de su capital nominal y el decimosexto por capital desembolsado ${ }^{32}$.

A la vez que invertía en minas, construcción y banca, Fierro creó o adquirió otro variado grupo de empresas en los años treinta. Al inicio de la década se asoció con unos empresarios de Burgos para fundar la Sociedad Española de Seda Artificial. Poco después compró a unos empresarios barceloneses la Sociedad Manufactura del Ferro Cerio Español, una empresa de manufacturas metálicas que fabricaba, entre otras cosas, piedras de ignición para encendedores ${ }^{33}$. En 1935 adquirió, junto al Banco de Valencia, los activos de una empresa en disolución, Bética, S. A., que le permitieron crear la sociedad Azucarera de Sevilla y constituyó una pequeña empresa de perfumería llamada Quimiflor ${ }^{34}$.

Otra de las aventuras de aquellos años previos a la guerra civil fue la entrada de los Fierro en el sector eléctrico a través de la compra de Hidroeléctrica del Guadiela, una sociedad fundada en 1925 para el aprovechamiento del río del mismo nombre y de su afluente, el río Cuervo. Sin embargo, el negocio eléctrico era muy complejo y la competencia de otras dos sociedades en la zona, Centrales Eléctricas Navarro y Buenamesón, le forzaron a vender la eléctrica del Guadiela a la familia Navarro y al conde de Romanones justo después de la guerra civil española ${ }^{35}$. No fue el único negocio que vendió: tampoco cuajó la aventura de Azucarera de Sevilla, que fue comprada por Azucarera del Ebro, ni la Sociedad Española de Seda Artificial, que quedó en manos de algunos de los socios que la había fundado.

Entre el grupo de empresas variopintas creadas o compradas por Fierro en los años treinta, hay dos que merecen atención por la importancia que alcanzaron años después: Cervantes, S. A., e Industrias subsidiarias de Aviación, S. A.

Ildefonso Fierro compró en 1934 Cervantes, S. A., Compañía Española de Seguros, una sociedad especializada en seguros de vida e incendios que se había creado en 1930. Cuando Fierro la adquirió, Cervantes llevaba unos años de trayectoria difícil, muy acordes con la coyuntura económica. El

\footnotetext{
31 Cien años de Vida en el Banco de Valencia, p. 58.

32 Anuario Financiero de Bilbao que comprende el historial de valores públicos y de sociedades anónimas de España, Banco de Vizcaya, 1936. Cuadro anexo.

33 Anuario Financiero y de Sociedades Anónimas de España (1933).

34 Anuario Financiero y de Sociedades Anónimas 1936. "Acción de Azucarera de Sevilla», Archivo Fierro, R. 482. «Informe del Banco de España sobre Quimiflor», Archivo Fierro, R. 448.

35 Datos facilitados por D. Virgilio Navarro en entrevista concedida el 7-05-2009.
} 
empresario leonés asumió la presidencia, mantuvo a algunos de los antiguos propietarios en el Consejo e incorporó a Enrique Navarro Reverter y a su hermano Félix, que fue nombrado Consejero Delegado. Con los años, Cervantes, S. A., alcanzó cierta importancia al convertirse en la aseguradora de empresas y empleados del Grupo Fierro.

Industrias Subsidiarias de Aviación fue constituida, en plena guerra civil, el 14 de noviembre de 1938 en la ciudad de Sevilla, donde la familia Fierro había establecido su residencia ${ }^{36}$. Su objeto social era la fabricación de accesorios y demás efectos para aviones de combate y civiles, aunque pronto amplió su actividad a los componentes de automóviles. Esta empresa terminó convirtiéndose en auxiliar de FASA Renault, otra de las sociedades en las que entró Fierro y que llegó a controlar justo antes de su fallecimiento ${ }^{37}$.

Para cerrar la descripción de los negocios de Fierro anteriores a 1939 hay que señalar su presencia como consejero en tres empresas que no eran de su propiedad: el Banco de Valencia, que acabo de citar, CAMPSA y la Sociedad Metalúrgica Duro Felguera. El caso de CAMPSA resulta interesante porque resalta una de las características del empresario leonés sobre la que volveré más adelante: su filiación con los monopolios. Fierro fue nombrado consejero de CAMPSA, representando al Banco Herrero, en 1928, y pasó a formar parte, además, del comité directivo del monopolio. Este comité, formalmente delegado del Consejo, era el organismo que regía los destinos de la empresa y tomaba las decisiones, mientras que el Consejo se limitaba a sancionarlas.

La relación de Fierro con Duro Felguera se remonta a los años veinte. Desde 1927, al menos, Fierro consta como consejero de la sociedad del Banco Urquijo. Fierro había fundado su naviera con ayuda de este Banco, y cuando llegó a la capital, estableció su cuartel general en unas oficinas alquiladas a la entidad financiera, en su edificio de la calle Barquillo núm. 1. Sin embargo, parece que el papel inicial desempeñado por el Urquijo en los negocios de Fierro perdió importancia a medida que la ganaron, primero el Herrero y el Hispano Americano, de los que Fierro fue accionista, y después el Banco Internacional de Industria y Comercio. Tras la guerra civil la familia Urquijo y Fierro siguieron coincidiendo en los Consejos de Tabacalera y CAMPSA, y el empresario leonés continuó en Duro Felguera, pero esta presencia era, sobre todo, el recuerdo de una antigua relación.

36 «Industrias Subsidiarias de Aviación», Banco de España, Archivo Histórico, Operaciones, Leg. 299. Sobre la fábrica de la empresa véase Sobrino (1998, pp. 98-99).

37 Los Fierro entraron en Fasa Renault en 1954. Poco después lo hizo el Banco de Santander, que controló la empresa hasta 1961. En febrero de ese año, el Banco Ibérico, propiedad de Fierro, compró al Santander sus acciones y dirigió la empresa automovilística como propietario mayoritario hasta 1965, año en que tuvo que ceder el paquete mayorista a la Régie Nationale des Usines Renault, aunque continuó como accionista minoritario. Fernández de Sevilla (2006, pp. 61-68). 


\section{UN ALTO EN EL CAMINO: LOS NEGOCIOS DE FIERRO EN 1939}

El resumen de los negocios que poseía Ildefonso Fierro en 1939 permite tres tipos de análisis: un análisis sectorial, un análisis de las personas o de las relaciones que se vislumbran tras sus empresas y, por último, un análisis sobre el modo en que las gestionaba.

Desde el punto de vista sectorial, el cuadro A del Apéndice muestra las cinco grandes líneas de negocio y el grupo de empresas variopintas que Fierro tenía hacia 1939 y cuyo nacimiento acabo de describir. Tres de las líneas de negocio más antiguas, «minería y su transformación», "fósforos» y «construcción y cemento», eran actividades netamente industriales. En todas ellas, Fierro había manifestado cierto afán por integrar verticalmente la producción. Por ejemplo, la compra de minas había ido acompañada de la creación de una naviera, cuarta línea de negocio, para transportar el mineral. A los fósforos había sumado la creación de una sociedad subsidiaria para elaboración de la publicidad y la distribución (Compañía Industrial Expendedora) y una empresa que fabricaba piedras de ignición para encendedores (Manufactura del Ferro Cerio); y la Constructora Fierro se había constituido al mismo tiempo que se compraba la Compañía Anglo-Española de Cemento Portland el León. A este innegable intento de integración vertical, Fierro había añadido un crecimiento horizontal: había ampliado el número de empresas mineras y, en el caso de los fósforos, había iniciado incluso la expansión internacional a través de Fosforeira Portuguesa.

Dado que las cuatro líneas de negocio prioritarias de Fierro eran intensivas en capital, no es de extrañar que apuntalara su crecimiento desde el punto de vista financiero. Por ello la quinta línea de negocio no es otra que su participación en banca como importante accionista del Hispano Americano y, sobre todo, mediante la compra del Banco Internacional de Comercio e Industria.

En el grupo de actividades que he definido como "variopintas» hay tres que fueron vendidas enseguida: Hidroeléctrica del Guadiela, Azucarera de Sevilla y la Sociedad Española de la Seda Artificial. Junto a ellas aparece Quimiflor, otra actividad industrial que tuvo su importancia en la posguerra. Las más notables de este variado grupo de empresas, por tamaño, son la aseguradora Cervantes e Industrias Subsidiarias de Aviación.

Hay dos notas que definen, desde el punto de vista sectorial, los negocios del empresario leonés. La primera de ellas es su vinculación a los monopolios. Dos de los cuatros monopolios arrendados que existían en España en 1939, la Arrendataria de Fósforos y la Compañía Industrial Expendedora, eran propiedad de Fierro. La presencia del empresario leonés era además muy importante en el Monopolio de Petróleos. Sólo el Monopolio de Tabacos escapaba a sus manos y fue por poco tiempo: en 1945 Fierro entró en Tabacalera, S. A., como accionista y Consejero. A pesar de la diversificación de sus negocios, los Fierro manifestaron cierta predilección por sectores en 
los que no existía competencia. También en sus salidas al exterior Fierro buscó mercados protegidos como Portugal, que desde 1926 se había convertido en una dictadura militar, y el Marruecos español de la posguerra. Es preciso recordar que esa participación en los monopolios no fue exclusiva de Fierro, sino bastante frecuente entre las familias empresarias españolas de la época. Los Herrero, por ejemplo tuvieron importantes participaciones en el monopolio de petróleos, tabacos y fósforos, y los Urquijo en los dos primeros citados y en los teléfonos ${ }^{38}$.

La segunda nota tiene que ver con el origen de la fortuna de Fierro. El empresario leonés mostró ser un auténtico especialista de los negocios en tiempo de guerra. Lo fue durante la gran guerra, obteniendo notables beneficios con la venta y transporte de carbón. Lo fue en la guerra civil, aprovechando para establecerse en el protectorado español y para fundar Industrias Subsidiarias de Aviación. Y aunque queda ya fuera del ámbito cronológico de estas páginas, lo fue en la Segunda Guerra Mundial, explotando de nuevo con increíble provecho los yacimientos mineros de wolframio ${ }^{39}$.

Tan interesante como el análisis sectorial resulta el análisis de las amistades que el empresario leonés había forjado en torno a sus negocios y que tenía un triple vértice: los Fierro, los Navarro Reverter y los Herrero. Como se observa en el cuadro B del Apéndice, en la constitución de la Arrendataria de Fósforos aparecen por primera vez las tres familias juntas. A partir de ese momento se multiplicaron sus actividades comunes: los Navarro-Reverter y los Herrero acompañaron a Fierro en la constitución de la Fosforeira Portuguesa y de la Constructora Fierro, de la que Ignacio Herrero era vicepresidente. Los Navarro-Reverter lo hicieron también en la cementera de Matillas, en la aseguradora Cervantes y en la Hidroeléctrica del Guadiela. Y Juan Navarro-Reverter, esta vez en sentido inverso, fue quien facilitó a Ildefonso Fierro el acceso al Banco de Valencia para la compra del Banco Internacional de Comercio e Industria. En el Banco de Valencia, Fierro hizo mucha amistad con Ignacio Villalonga, que se incorporó como consejero al Banco Internacional de Industria y Comercio hasta la guerra civil y que en 1940 se incorporó al Banco Central. Esa amistad está en el origen de la fusión que se produjo entre el Central y el Banco Internacional en el año 1943 y que duró sólo tres años ${ }^{40}$.

Las relaciones de Fierro con la familia Herrero quedaron reforzadas por otras dos actividades: Ignacio Herrero de Collantes pidió al empresario leonés que representara al Banco Herrero en el Consejo de la CAMPSA y Fierro se convirtió en un importante accionista del Banco Hispano Americano.

38 Véase Puig y Torres (2008, pp. 66-71) y Anes y Otazu (1987, pp. 162-174).

39 Carmona (2003, pp. 261-280).

40 En 1946 las diferencias entre Fierro y Villalonga, dos personas de gran carácter, condujeron a la salida de Fierro del Central y a la fundación del Ibérico. Sobre Ignacio Villalonga Villalba (1895-1973) hay una biografía escrita por Gabriel Tortella en Torres (2000). 
Fierro cuidó siempre de modo extraordinario sus relaciones personales. No sólo los vínculos de amistad con quienes fueron sus compañeros de negocios, sino los vínculos con los políticos que le facilitaron, en muchos casos, sus actividades económicas. Fue, por ejemplo, amigo personal de José Calvo Sotelo, que ostentó la cartera de Hacienda entre 1925 y 1930. La relación con Calvo Sotelo se remonta a la participación de Fierro en la creación de CAMPSA y no se trató de un contacto puramente protocolario: cuando Calvo Sotelo abandonó la cartera ministerial, prestó servicios jurídicos como abogado en los negocios de Fierro. Por amistad y afinidad política con él, Fierro financió las actividades del Bloque Nacional en tiempos de la República $^{41}$. Y, tras el asesinato de Calvo Sotelo, el empresario leonés ofreció a su viuda, en prueba de su profundo afecto y respeto, un cheque en blanco que no fue aceptado pero que reforzó los lazos de amistad con la familia ${ }^{42}$. Es evidente que en 1939 Fierro se encontraba extraordinariamente bien situado desde el punto de vista político, cosa que resultaba vital para el desarrollo de cualquier negocio en España.

Todo lo expuesto hasta el momento permite vislumbrar cuatro rasgos sobre el modelo de gestión empresarial que había desarrollado el empresario leonés. En primer lugar, se podría decir que Fierro dirigía los negocios personalmente y con mucha autoridad: era el presidente de la mayor parte de las sociedades de su propiedad y todos los asuntos de sus empresas pasaban por sus oficinas de la calle Barquillo. Esa dirección personal incluía, además, una extensa red de relaciones que abarcaba a políticos y hombres de negocios.

En segundo lugar, cabría destacar la inclinación de Fierro a rodearse de personas de confianza para la dirección de sus negocios. Mientras pudo contó con sus hermanos y después incorporó a sus hijos y yernos. Por otra parte, nunca dejaron de acompañarle sus «amigos de toda la vida»: Luis Martínez Sánchez y Félix Monzón, una suerte de «familia extensa» para el empresario leonés. En este sentido parece que Ildefonso Fierro valoró más la confianza que la cualificación.

En tercer lugar destaca la audacia del empresario leonés, que se tradujo en un fuerte afán por diversificar sus negocios y que le ganó, en más de una ocasión, el calificativo de «arriesgado» u «osado», en su expediente del Banco de España ${ }^{43}$.

41 El Bloque Nacional fue concebido por Calvo Sotelo como una alianza o bloque para agrupar a todas las fuerzas de la derecha antirrepublicana que no aceptaban la Constitución de 1931. A la iniciativa se sumaron los tradicionalistas y Renovación Española, el partido monárquico Alfonsino. De la relación de Calvo Sotelo con Fierro dio cuenta Pedro Sainz Rodríguez en «Víctor Pradera en mi recuerdo», publicado en la tercera de $A B C$ el 4-9-1986. También está en Sainz Rodríguez (1978, p. 211).

42 Dos de los hijos de Calvo Sotelo escribieron necrológicas a la muerte de Fierro manifestando su admiración y afecto y narrando el asunto del cheque en blanco. "Un creador impar», en $Y a$, 9-12-1961.

43 Banco de España, Archivo Histórico, Operaciones, Leg. 297, expediente 285. 
En cuarto lugar, Fierro diversificó sus actividades creando empresas autónomas, pero estableció fuertes relaciones entre ellas. Cervantes, por ejemplo, se convirtió en la aseguradora de empleados y empresas de Ildefonso Fierro. Por su parte, la Sociedad Comercial Asturiana se hizo cargo de la representación de Fosforería Portuguesa y se convirtió en Delegada de la aseguradora Cervantes. La mayoría de estos rasgos se afianzaron y ahondaron después de la guerra civil.

\section{MIRANDO A ORIENTE: PARECIDOS Y DIFERENCIAS CON LOS ZAIBATSU}

Para comprender por qué he calificado el caso Fierro como un «zaibatsu fuera de lugar» conviene repasar algunos aspectos teóricos sobre esta legendaria institución japonesa ${ }^{44}$.

Un zaibatsu era un grupo diversificado de empresas que pertenecían exclusivamente a una familia ${ }^{45}$. Los zaibatsu alcanzaron su madurez en las primeras décadas del siglo xx y dominaron numerosos sectores de la economía japonesa hasta que fueron disueltos, en los años de la ocupación aliada que siguieron a la Segunda Guerra Mundial.

Hay quienes piensan que zaibatsu es sinónimo de empresas enormes que operaban como oligopolios dominando sectores clave de la economía japonesa. Sin embargo, esta definición se corresponde sólo con una pequeña parte de los zaibatsu, aunque sean los más conocidos. Como ha explicado Morikawa, no todas las grandes empresas que existían en Japón antes de la Segunda Guerra Mundial eran zaibatsu y no todos los zaibatsu fueron grandes empresas. Existieron zaibatsu de los más variados tamaños: desde los gigantes y famosos como Mitsui, Mitsubishi y Sumimoto hasta una infinidad de ellos, de talla media y minúscula, completamente desconocidos ${ }^{46}$. Tam-

44 La literatura sobre los zaibatsu es muy extensa. Una buena síntesis de todos los estudios que se han hecho sobre esta institución es la de Naofumi (2002). Para mi propósito me he servido, sobre todo, de los trabajos de Morikawa (1970, 1988 y 1995), Nakagawa (1996) y Shimotani (1997). Morikawa (1995) me ha resultado especialmente útil puesto que resume muchos otros trabajos no traducidos del japonés.

45 Sobre la definición de zaibatsu véase Morikawa (1995, pp. xvii-xviii) y Tang (2008, pp. 3-5).

46 Mitsubishi fue fundado en 1870 por Iwasaki Yataro (1835-1885). A finales del siglo XIX, pasó de los negocios marítimos a un proceso de diversificación que terminó con la creación de tres entidades: Mitsubishi Bank, Mitsubishi Corporation, para la financiación interna del grupo y Mitsubishi Heavy Industries que englobaba las actividades industriales del grupo: motores, energía nuclear, química, eléctrica, material de fotografía y componentes electrónicos y ordenadores. Sumimoto toma el nombre de su fundador, Masatomo Sumitomo (1585-1652), que comenzó vendiendo medicamentos y libros en el siglo XVII. Sus primeros negocios relevantes son los relacionados con la minería del cobre, y a finales del XIX empezó la diversificación hasta abarcar una multitud de negocios. El zaibatsu Mitsui tiene su origen en Mitsui Takatoshi (1622-1694). Pertenecía a una familia de comerciantes y empezó con una empresa textil de kimonos, que aún sigue existiendo, y con un negocio de cambio de moneda. El zaibatsu Mitsui fundó su primer banco, Mitsui Bank, en 
poco puede confundirse zaibatsu con empresa familiar, sin más. El origen del zaibatsu estaba, efectivamente, en empresas familiares, algunas creadas en la época del Shogunato Tokugawa (1603-1868) y otras al comienzo de la era Meiji (1868-1912). Sin embargo, no todas las empresas familiares alcanzaron el grado de diversificación que les permitió dejar de serlo y recibir un nuevo nombre.

La mayoría de los zaibatsu tuvieron como punto de arranque unos negocios modestos, ligados a actividades comerciales de alimento, ropa o calzado. Muchos de ellos crecieron y se expandieron durante la era Meiji vinculándose a la actividad minera. Así sucedió con Sumimoto y Furukawa, ambos relacionados con la explotación de minas de cobre ${ }^{47}$. El salto adelante se les facilitó, en algunos casos, por la concesión de monopolios y ayudas diversas del Estado y por la adquisición de empresas públicas a precios ventajosos. Esta colaboración del gobierno Meiji en la creación de algunos zaibatsu no fue deliberada, sino una consecuencia de la necesidad de paliar el déficit público que había provocado la política industrializadora de los comienzos de la era Meiji ${ }^{48}$. Zaibatsus como Mitsui, Mitsubishi, Yasuda Okura y Fujita, por citar algunos ejemplos, pertenecen al grupo de los beneficiados, en su despegue, por el Estado ${ }^{49}$. Aunque la autoridad pública favoreció la creación de algunos zaibatsu a través de los medios que acabo de indicar,

1876. Fue el zaibatsu al que más benefició la Primera Guerra Mundial y, como consecuencia, vivió una amplia diversificación: desarrolló empresas mineras, navieras de seguros, y numerosas ramas industriales. Entre las empresas más destacadas que formaron parte de este zaibatsu se cuentan Tohiba y Toyota Motors. La historia de estos Zaibatsu la recoge Morikawa (1995). Sobre Mitsubishi y Mitsui véase también Morikawa (1970).

47 Furukawa Group es ahora uno de los 15 mayores grupos industriales de Japón. Su origen se remonta a 1875 y fue fundado por Furukawa Ichibei. Hasta la Segunda Guerra Mundial este zaibatsu se especializó en minería electrónica e industria química. Entre sus principales empresas hoy día se cuentan Fuji Electric, Furukawa Electric, Fujitsu, FANUC y Advantest.

$48 \mathrm{Al}$ inicio de la era Meiji el estado había invertido en la construcción de infraestructuras y había creado numerosas empresas públicas. Para financiar la expansión del gasto, el gobierno japonés recurrió a los préstamos, pero, sobre todo, recurrió a la emisión de dinero provocando una inflación que se agudizó a finales de los años setenta. En 1882, el ministro de Hacienda, Matsukata reorientó la política económica del Estado, vendió la mayoría de las empresas públicas, paró las subvenciones e impuso una rígida disciplina presupuestaria. Las medidas de Matsukata provocaron a corto plazo una contracción de la oferta monetaria y una recesión económica moderada. Sin embargo fueron el precedente, la condición sine qua non, del crecimiento económico que se inició a mediados de los años ochenta. Macpherson (1992, pp. 35-40).

49 Mitsui y Yasuda realizaron tareas financieras para el Shogunato Tokugawa. Básicamente gestionaron un sistema de letras de cambio que evitó al Shogunato el movimiento físico de los fondos recaudados por la venta de arroz en lugares lejanos a la capital. Okura hizo una fortuna como proveedor de pertrechos militares, básicamente textiles y botas, durante la era Meiji. Fujita también fue proveedor de bienes y constructor de obra pública para el nuevo régimen y Mitsubishi creció gracias a la protección estatal, ya que sus barcos actuaron como transportistas del gobierno Meiji. Morikawa (1995, p. 5-15). Algunos estudiosos han afirmado que los zaibatsu deben su crecimiento exclusivamente a la ayuda del gobierno. Tang (2008, p. 4), rebate esta visión con contundencia. Entre otras cosas recuerda que los zaibatsu nunca recibieron ayudas proporcionales al riesgo que asumieron. 
la mayoría de los zaibatsu que tuvieron una larga y exitosa supervivencia, se desprendieron, en algún momento de su historia, de cualquier relación política para no depender en exceso de unas circunstancias, por su misma naturaleza, inestables ${ }^{50}$. Fueron también muchos los zaibatsu que se formaron sin ayuda estatal, antes de la era Meiji y operando en sectores a los que la autoridad pública prestó poca atención.

Todos los grandes zaibatsu, y la mayoría de los pequeños, solían tener sus cuarteles generales en una de las grandes ciudades japonesas, Tokio, Osaka, Yokohama o Kobe. El resto de los pequeños zaibatsu estaban emplazados en ciudades secundarias. Se les conoce con el nombre de «zaibatsu locales» y algunos de esta categoría, los menos, alcanzaron tamaño y renombre con el paso de los años, como Bridgestone y Kikkoman ${ }^{51}$. La mayoría de los zaibatsu, aunque ni todos ni siempre, se organizaron a través de una red de empresas filiales ${ }^{52}$ : cada nuevo negocio se establecía en principio como una división de la sociedad matriz, pero al poco tiempo se independizaba para dar lugar a una nueva sociedad, muchas veces anónima. Esta forma de organización dotaba a las empresas de una autonomía que facilitaba su crecimiento. El control de la filial estaba asegurado, puesto que los tenedores de sus acciones eran la misma familia empresaria, a través de otro de sus negocios o directamente. Tal modo de proceder explica la formación de importantes holdings como estructura de organización de muchos de los grandes zaibatsu.

Aunque la propiedad de los zaibatsu era siempre de la familia, para la dirección de los negocios recurrieron, en múltiples ocasiones, a gerentes asalariados altamente cualificados que llevaron a cabo la diversificación ${ }^{53}$. En otras ocasiones fueron individuos incorporados a la familia por vía matrimonial los que se hicieron cargo de la dirección de las empresas. Como explica para el caso Toyota, Landes (2006, pp. 215-216), el modelo familiar japonés era más complejo que el occidental y en Japón los maridos podían incorporarse a la familia de la esposa con todos los derechos de un hijo biológico.

50 Morikawa (1995, pp. 20-24).

51 Bridgestone Corporation es una multinacional cuyo origen se remonta a 1931. Fue fundada por Shojiro Ishibashi (1889-1976) en la ciudad de Kurume, Prefectura de Fukuoka. Se dedicó desde el principio a la producción de elementos de caucho y pasó de fabricar suelas de zapatos a neumáticos para vehículos. En 1988 compró Firestone. Kikkoman Corporation es una empresa fundada en 1917 en la ciudad de Noda, Prefectura de Chiba. Es el resultado de la combinación de ocho negocios familiares de la familia Mogi, cuyo origen se remonta al siglo XVII. Sus principales productos y servicios son alimentarios: Kikkoman es una de las marcas de salsa de soja más conocidas en el mundo.

52 Sobre la estructura de los zaibatsu véase Shimotani (1997).

53 El recurso a gerentes externos para las empresas es muy antiguo en Japón. Ya en la era de los Tokugawa (1603-1868) era habitual entre los grandes mercaderes el reclutamiento, entre los empleados más competentes, de personas a las que se les delegaban funciones gerenciales. Kobayashi y Morikawa (1985, pp. x-xi). También Morikawa (1985, pp. 1-27). 
Las estrategias que los zaibatsu siguieron para diversificarse resultaron, a veces, un poco erráticas. El variopinto rumbo de las inversiones se ha atribuido, por una parte, al reducido tamaño del mercado interior, que les impedía especializarse y, por otra, a que la mayoría de los recursos de capital eran propiedad de los zaibatsu, lo cual les permitía invertir en todos los negocios con perspectivas razonables de rentabilidad ${ }^{54}$. Sin embargo, de estos dos argumentos sólo el segundo parece sostenible, porque en aquellos años el mercado japonés no dejó de crecer gracias a la política expansionista del gobierno ${ }^{55}$.

El zaibatsu no fue un fenómeno exclusivamente japonés. Exclusiva de Japón fue la multitud de ellos que se formaron en los años clave de la industrialización del país y el papel que jugaron en aquellos momentos decisi$\operatorname{vos}^{56}$. Como recordé al inicio de estas páginas, diversos estudiosos han insistido en que pueden encontrarse instituciones parecidas en otros lugares ${ }^{57}$. Me parece que el caso Fierro puede ser una de ellas, aunque mantenga sus propias peculiaridades e incluso sus diferencias. En las antípodas geográficas y con un tamaño mucho menor, pero coincidiendo temporalmente, la actividad de Fierro presenta, al menos, cinco similitudes con los zaibatsu.

En primer lugar, sus orígenes. En este sentido, el imperio de Fierro tuvo unos comienzos modestos vinculados a una actividad comercial de importancia menor como era la venta de carbón y pescado. El despegue llegó de la mano de la actividad minera y vinculado, sobre todo, a la coyuntura bélica de 1914 y a la consiguiente expansión de la demanda de minerales que provocó el conflicto. También Fierro aprovechó las necesidades presupuestarias del Estado para acceder a la concesión del Monopolio de Fósforos.

En segundo lugar la diversificación, que es la característica distintiva de los zaibatsu junto a su carácter familiar ${ }^{58}$. En este sentido, Fierro manifestó muy pronto su tendencia a no anclarse en un solo sector. Igual que sucedió en muchos de los zaibatsu de la primera hora, Fierro diversificó sus empresas un tanto erráticamente, aprovechando las oportunidades de negocio que le brindó el pequeño tamaño del mercado español.

En tercer lugar, la diversificación de Fierro no se hizo a través de una única empresa. Al igual que muchos zaibatsu, el empresario leonés optó por un sistema de empresas autónomas cuya propiedad estaba siempre en sus manos, directamente, o través de las empresas del grupo. Así, la Sociedad Comercial Asturiana se convirtió en una sociedad de valores, tenedora de acciones de otras sociedades del grupo, como por ejemplo, Quimiflor. En los

54 Nakagawa (1996, pp. 302-310).

55 Desde finales del siglo xIx y hasta la Segunda Guerra Mundial, gracias a la política de expansión, Japón incorporó la Isla de Formosa y Corea, primero, y la península de Manchuria después.

56 Sobre el papel de los zaibatsu en la industrialización, véase Miyamoto (1984, pp. 39-91).

57 Morikawa (1995, p. xvii).

58 La diversificación de los zaibatsu es una de las características que, en opinión de Tang (2008, p. 2), les facilitó su carácter de pioneros frente a sus competidores. 
años que abarca este trabajo, la propiedad de la mayoría de las empresas de Fierro permaneció, no obstante, directamente en la familia.

En cuarto lugar, Fierro creó, como muchos zaibatsu, empresas de distribución —valga el ejemplo de la Comercial Asturiana- y compró un banco para facilitar el desarrollo de sus empresas. El empresario leonés empezó siendo accionista de un gran banco, el Hispano, pero pronto optó por adquirir uno propio. Sus posibilidades financieras sólo le permitieron hacerlo en 1932, en asociación con otra entidad financiera española, el Banco de Valencia, pero en cuanto pudo - y no tardó mucho en llegar-, Fierro fundó un banco enteramente suyo, el Ibérico, que nació en 1946.

En quinto lugar, también la Primera Guerra Mundial fue un momento clave para Fierro, como lo fue para muchos zaibatsu. La neutralidad japonesa, como la española, proporcionó una ocasión única de crecimiento. La crisis de posguerra también fue una prueba de fuego para todos los que se habían aprovechado de la excepcionalidad y no todos supieron afrontar las dificultades de la vuelta a la normalidad. En Japón los que lograron superarlas lo hicieron: i) a través de una organización más racional de la producción; ii) en algunos casos integrando verticalmente la producción a través de la creación de empresas que, por ejemplo, consumieran los minerales que ya no se colocaban tan fácilmente, y iii) dirigiendo su actividad hacia nuevos sectores. También Fierro lo hizo. Disminuyó la producción minera en 1921 y esperó mejores tiempo; integró verticalmente en los fósforos y en la construcción y, sobre todo, abandonó Asturias y se trasladó a Madrid en busca de nuevas oportunidades.

Los parecidos del caso Fierro con los zaibatsu no pueden ocultar sus diferencias, especialmente dos muy notables. La primera es que Fierro rechazó la gestión externa para la dirección de sus negocios, asumió personalmente esta tarea y, como máximo, la compartió con sus hijos varones. La segunda es que los zaibatsu compitieron ferozmente entre sí, mientras que Fierro operó en mercados protegidos y con escasa o ninguna competencia. La competencia y el liderazgo de sus cualificados directivos otorgaron a los zaibatsu un carácter innovador y los convirtieron en protagonistas de la industrialización japonesa.

Aún es pronto para extraer conclusiones sobre el caso Fierro más allá de las reflexiones que acabo de hacer, o para asegurar que el declive de esta empresa familiar, ocurrido en los años ochenta, tuvo que ver con las diferencias que he señalado y que facilitaron el éxito de algunos zaibatsu. Asegura Morikawa que el fracaso de muchos zaibatsu de la primera hora se explica porque no supieron desvincularse del gobierno y esta dependencia les provocó inestabilidad. Quizá el caso de Fierro sea exactamente el contrario: la protección le proporcionó una estabilidad excesiva que aletargó sus posibilidades de adaptación al mercado abierto y su capacidad de innovación. De momento no puedo asegurarlo, pero lo cierto es que la comparación con los zaibatsu plantea, cuando menos, una interesante senda para continuar la investigación. 


\section{FUENTES}

Archivo Fierro: Al iniciar este trabajo propuse a la familia Fierro la creación de un archivo que no existía. Hasta el momento he recopilado más de quinientos documentos y numeroso material gráfico que he catalogado y digitalizado para crear el «Archivo Fierro» que cito en estas páginas. Los papeles recuperados los custodia la Familia Fierro-March en Madrid. La edición digital del Archivo se distribuirá oportunamente a todos los componentes de la familia que han colaborado en la investigación.

Banco de España: Archivo Histórico, Operaciones, Legajo 217 y 296 (varios expedientes).

\section{BIBLIOGRAFÍA}

AguirRe de ViaR, J. (1918): «Asturias». Revista Nacional de Economía, año III, t. IV, núm. 11, pp. 98-102.

ANes, R., y OtAzu, A. DE (1987): El banco Herrero. 75 años de Historia. 1912-1987.

Asturias y la mar (2006), Prensa Asturiana Editorial.

CARmona, X. (2003): «La minería española del wolframio 1936-1954, Los años de la fiebre», en G. Sánchez Recio y J. TAscón (coords.), Los empresarios de Franco. Política y Economía en España, 1936-1957, Barcelona: Crítica, pp. 261-280.

CARreras, A., y TAFunell, X. (1993): «La gran empresa en España (1917-1974). Una primera aproximación». Revista de Historia Industrial, núm. 3, pp. 127-175.

Cien años de vida en el Banco de Valencia, 1900-2000, Valencia: Banco de Valencia.

Cubillo de la Puente, R. (2006): Arrieros leoneses. La montaña central. Gordón Vegacervera, Los Argüelles. León: NC Comunicación.

Díaz Morlán, P. (2002): Los Ybarra. Una dinastía de empresarios. Madrid: Marcial Pons Historia.

- (2009): Capitalistas y empresarios. El mercado de la función empresarial. Alicante: Universidad de Alicante.

FERNÁNDEZ DE SEvilla, T. (2006): «De Ensambladores a fabricantes. Historia Económica de FASA, 1951-1965», monografía presentada para la obtención del DEA, Universidad de Barcelona (inédito).

FERnÁndez PÉREZ, P. (2003): «Reinstalando la empresa familiar en la Economía y la Historia económica. Una aproximación a debates recientes». Cuadernos de economía y dirección de la empresa, ISSN 1138-5758, núm. 17, 2003, pp. 45-66.

- (2004): Un siglo y medio de trefilería en España. Historia de Modera (1879-2004) y de Rivière (1854-2004). Barcelona: MRT Moreda-Rivière Trefilerías, S. A.

- (2005): «Redes familiares e innovación tecnológica en la España de fines del siglo xIx: los casos de José María Quijano y François Rivière». Historia contemporánea, núm. 31, 2005, pp. 439-456.

- (2006): «Empresas familiares y acuerdos cooperativos en el metal español: el caso de las industrias del alambre de hierro y acero (1880-1974)». Investigaciones de Historia Económica, núm. 4, 2006, pp. 51-76.

Fernández Pérez, P., y Puig Raposo, N. (2007): «Bonsais in a Wild Forest? A Historical Interpretation of the Longevity of Large Spanish Family Firms». Revista de Historia Económica. Journal of Iberian and Latin American Economic History, núm. 3, 2007, pp. 459-497. 
García RuIz, J. L. (1998): Cervezas Mahou 1890-1998. Un siglo de tradición e innovación. Madrid: Lid.

Gómez MendozA, A. (1987): «La formación de un cártel en el primer tercio del siglo xx: la industria del cemento portland». Revista de Historia Económica, año V, núm. 2, pp. 325-361.

- (1989): Ferrocarril, industria y mercado en la modernización de España. Madrid: Espasa Calpe.

GoÑI, I. (2009): "De Esperanza y Unceta a ASTRA-Unceta y Cía., S. A., una empresa armera ante el mercado internacional». Revista de Historia Industrial, 40, 2, pp. 51-94.

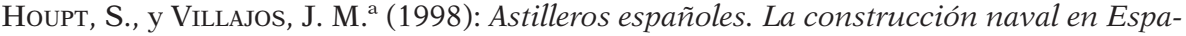
ña. Madrid: Lid.

Kobayashi, K., y MoriKawa, H. (1985): Development of Managerial Enterprise. The International Conference on Business History 12. Proceeedings on the Fuji Conference. Tokyo: University of Tokyo Press.

Lacomba, J., y RuIz, G. (1999): Una historia del Banco Hipotecario de España (18721986). Madrid: Alianza Editorial.

Landes, D. (2006): Dinastías. Fortunas y desdichas de las grandes familias de negocios. Barcelona: Crítica.

López Calle, P. (2004): Paternalismo industrial y desarrollo del capitalismo: la fábrica de cementos el león de Guadalajara, 1900-1930. Tesis Doctoral, Universidad Complutense de Madrid, Facultad de Ciencias Políticas y sociología, Departamento de Sociología III.

MacPherson, W. J. (1992): The Economic Development of Japan, c.1868-1941. London: Macmillan.

Martín Aceña, P. (2007): 1857-2007 Banco Santander: 150 años de Historia. Madrid: Turner Publicaciones.

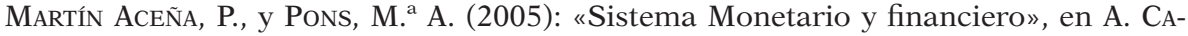
RRERAS y X. TAFunell (coords.), Estadísticas Históricas de España. Siglos XIX y XX, Madrid: Fundación BBVA, vol. 2, pp. 645-706.

Naofumi, N. (2002): «The Present State of Research on Zaibatsu: The Case of Mitsubishi». Social Science Japan Journal, 5, pp. 233-242.

Morikawa, H. (1970): «The Organizational Structure of The Mitsubishi, and Mitsui Zaibatsu, 1868.1922: A Comparative Study». Business History Review, XLIV, 1, pp. 62-83.

- (1985): «Prerequisites for the Development of Managerial Capitalism: Cases in Prewar Japan», en K. KobaYAshi y H. MoRiKawa (1985), Development of Managerial Enterprise. The International Conference on Business History 12. Proceedings on the Fuji Conference, Tokyo: University of Tokyo Press, pp. 1-27.

- (1988): "The Development of Multi-Industrial Concentration in Modern Japan», en H. Pohl y W. Treue (eds.), The Concentration Process in The Entreprenurial Economy Since the Late $19^{\text {th }}$ Century, Stuttgart: Steiner Verlag Wiesbaden.

- (1995): Zaibatsu. The Rise and Fall of Family Enterprise Groups in Japan. Tokyo: University of Tokyo Press.

NaKagaWA, K. (1996): «Business Management in Japan: A Comparative Historical Perspective». Industrial and Corporate Change, 2, 1, pp. 25-44.

Prados, L. (2003): El progreso económico de España (1850-2000). Bilbao: Fundación BBVA.

Puig Raposo, N. (2003): Bayer, Cepsa, Repsol, Puig. Schering y La Seda. Constructores de la química española, Madrid. 
Puig Raposo, N., y Fernández Pérez, P. (2008): «La gran empresa familiar española en el siglo xx: claves de su profesionalización». Revista de la historia de la economía y de la empresa, núm. 2, 2008, pp. 93-122.

- (2009): «A silent revolution: The internationalisation of large Spanish family firms». «The internationalization of large historical Spanish Family firms». Business History Review, 51: 3, pp. 462-483.

- (2009): «La internacionalización de la gran empresa familiar española», Revista de Información Comercial Española, núm. 849 (en prensa).

Puig, N., y Torres, E. (2008): Banco Urquijo. Un Banco con Historia. Madrid: Banco Urquijo Sabadell.

SalueÑA, A. (2007): «La economía del Protectorado durante la Guerra Civil». Revista de Estudios Internacionales Mediterráneos, REIM, núm. 3, septiembre-diciembre, pp. 5-20.

SHIMOTANI, M. (1997): «The History and Structure of Business groups in Japan», en T. Shiba y M. Shimotani (eds.), Beyond the Firm. Business Groups in International and Historical Perspective, Nueva York: Oxford University Press, pp. 5-28.

Tortella, G. (2000): «Prólogo», en E. Torres (dir.) (2000), Los 100 empresarios españoles del siglo XX, Madrid: LID, pp. 13-18.

Tortella, G., y García Ruiz, J. L. (1999): Una historia de los Bancos Central e Hispano Americano (inédito).

TorRes, E. dir (2000): Los 100 empresarios españoles del siglo XX. Madrid: LID.

VAldaliso, J. M. ${ }^{a}$ (2006): La familia Aznar y sus negocios (1830-1983). Cuatro generaciones de empresarios en la España Contemporánea. Madrid: Marcial Pons. 


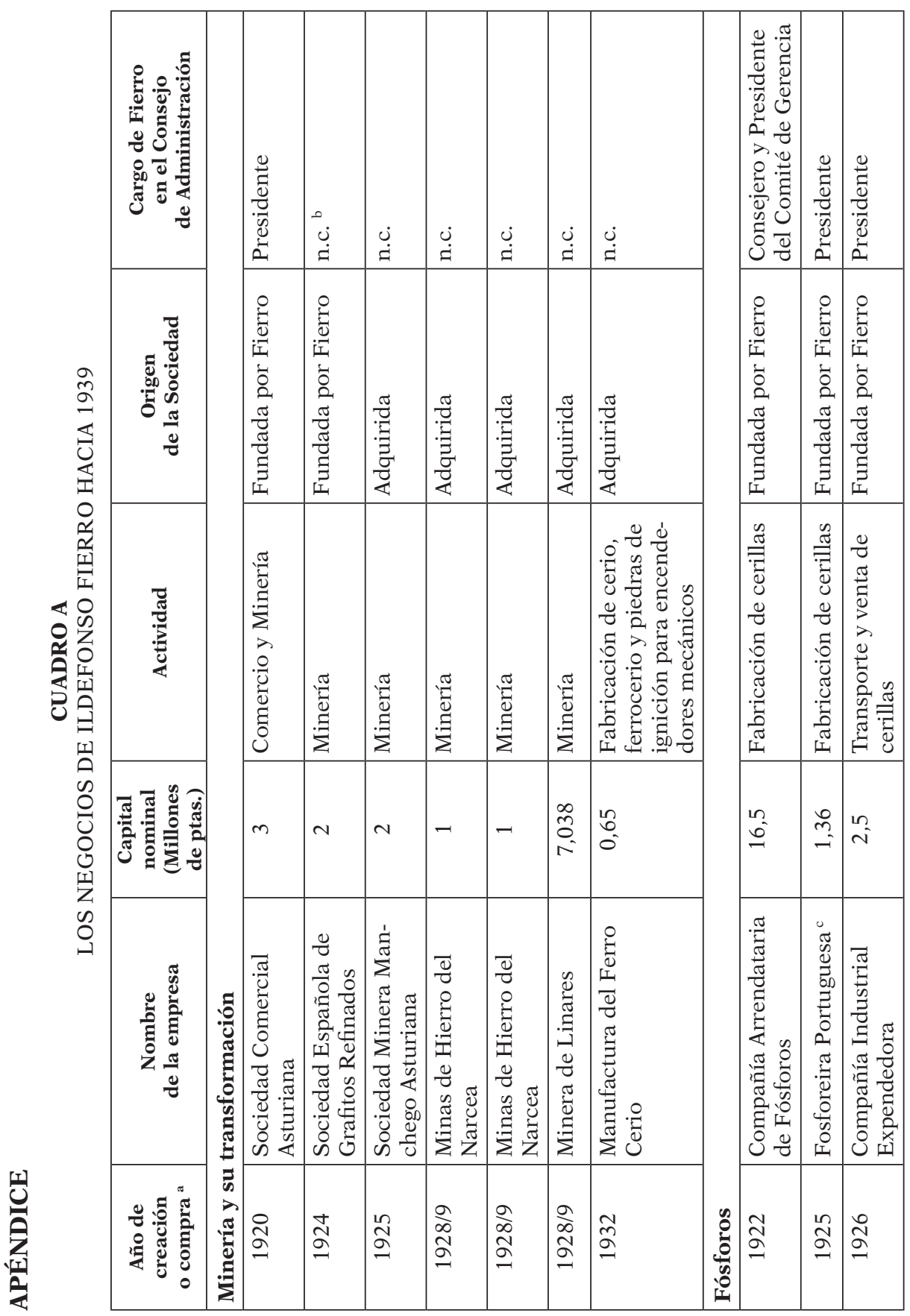




\begin{tabular}{|c|c|c|c|c|c|c|c|c|c|c|c|c|c|c|}
\hline 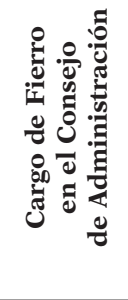 & 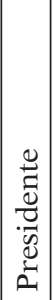 & 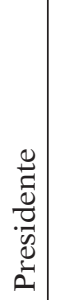 & & 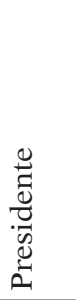 & 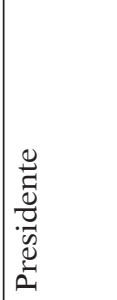 & 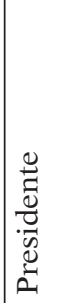 & & 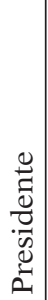 & & 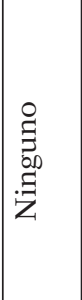 & 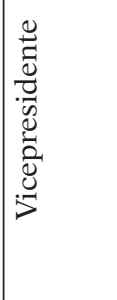 & & بُ & $\begin{array}{l}\frac{0}{0} \\
\frac{0}{0} \\
. \bar{d} \\
0 \\
0\end{array}$ \\
\hline 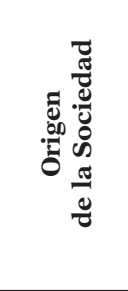 & 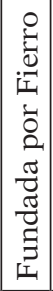 & 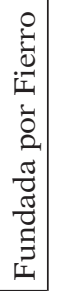 & & 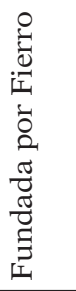 & 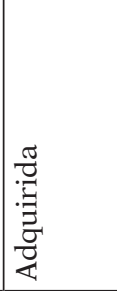 & 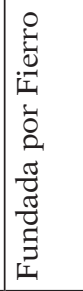 & & 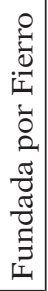 & & $\stackrel{0}{0}$ & $\stackrel{0}{0}$ & & 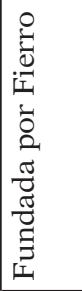 & $\begin{array}{l}\frac{\pi}{0} \\
\frac{\Xi}{\Xi} \\
\frac{\sigma}{2} \\
\frac{0}{2}\end{array}$ \\
\hline 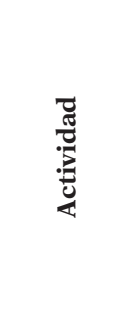 & 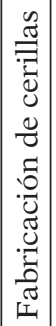 & 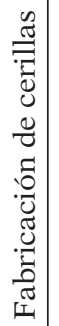 & & 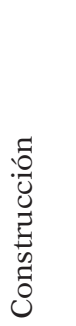 & 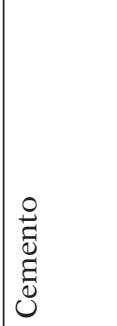 & $\begin{array}{l}: 0 \\
0 \\
0 \\
0 \\
己 \\
0 \\
0 \\
0 \\
0 \\
0\end{array}$ & & 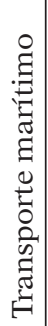 & & 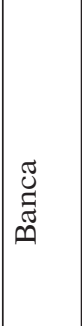 & 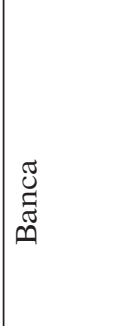 & & 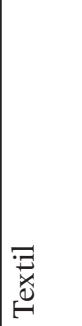 & 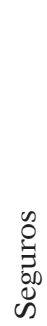 \\
\hline 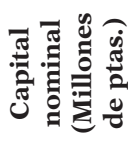 & $\begin{array}{l}10 \\
7\end{array}$ & $m$ & & $\stackrel{ }{=}$ & in & $\begin{array}{l}n \\
\text { no } \\
\text { in }\end{array}$ & & 으 & & ¿ & i & & 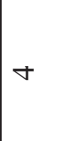 & $\stackrel{0}{ }$ \\
\hline 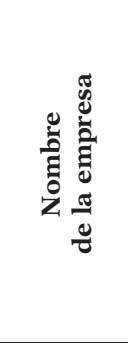 & 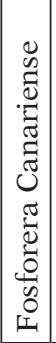 & 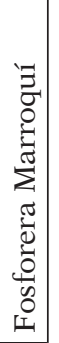 & 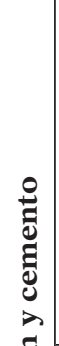 & 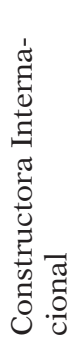 & 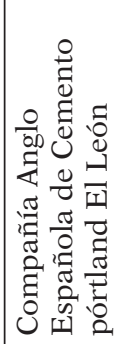 & 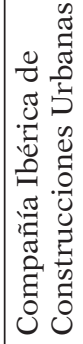 & & 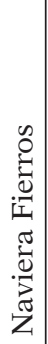 & & 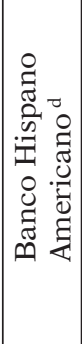 & 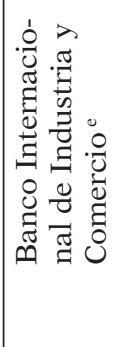 & & 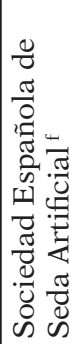 & 这 \\
\hline 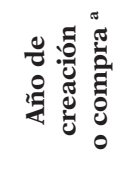 & $\begin{array}{l}\stackrel{n}{\sim} \\
\stackrel{\sigma}{\sigma}\end{array}$ & $\stackrel{\sim}{\tilde{a}}$ & 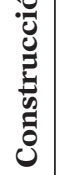 & ๙ૂ & సે & $\overrightarrow{\tilde{\alpha}}$ & $\frac{\pi}{0}$ & $\frac{a}{a}$ & 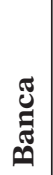 & ふָ & $\begin{array}{l}\tilde{N} \\
\tilde{\sigma}\end{array}$ & 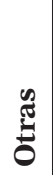 & ô & $\stackrel{+}{\stackrel{\sim}{a}}$ \\
\hline
\end{tabular}



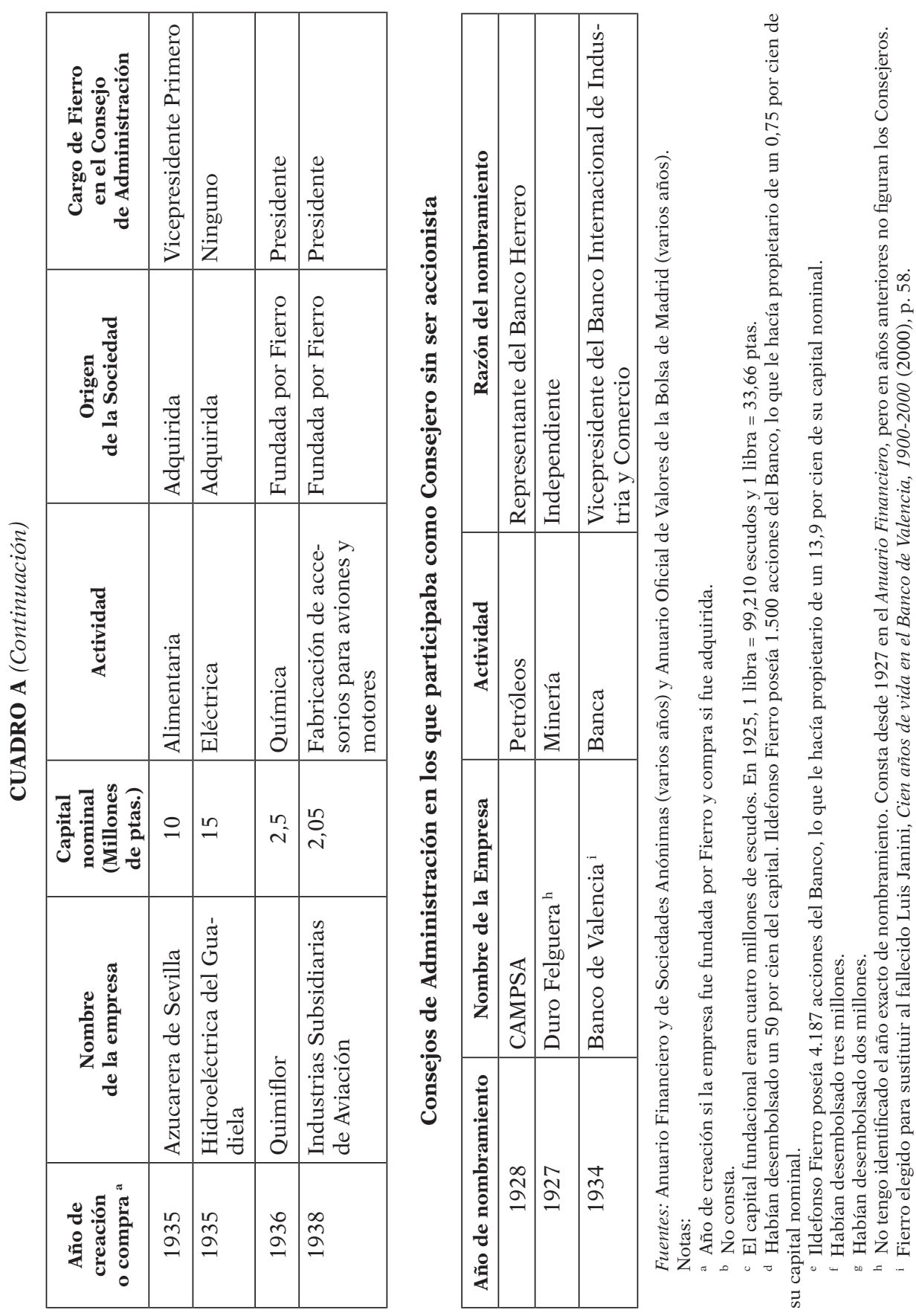


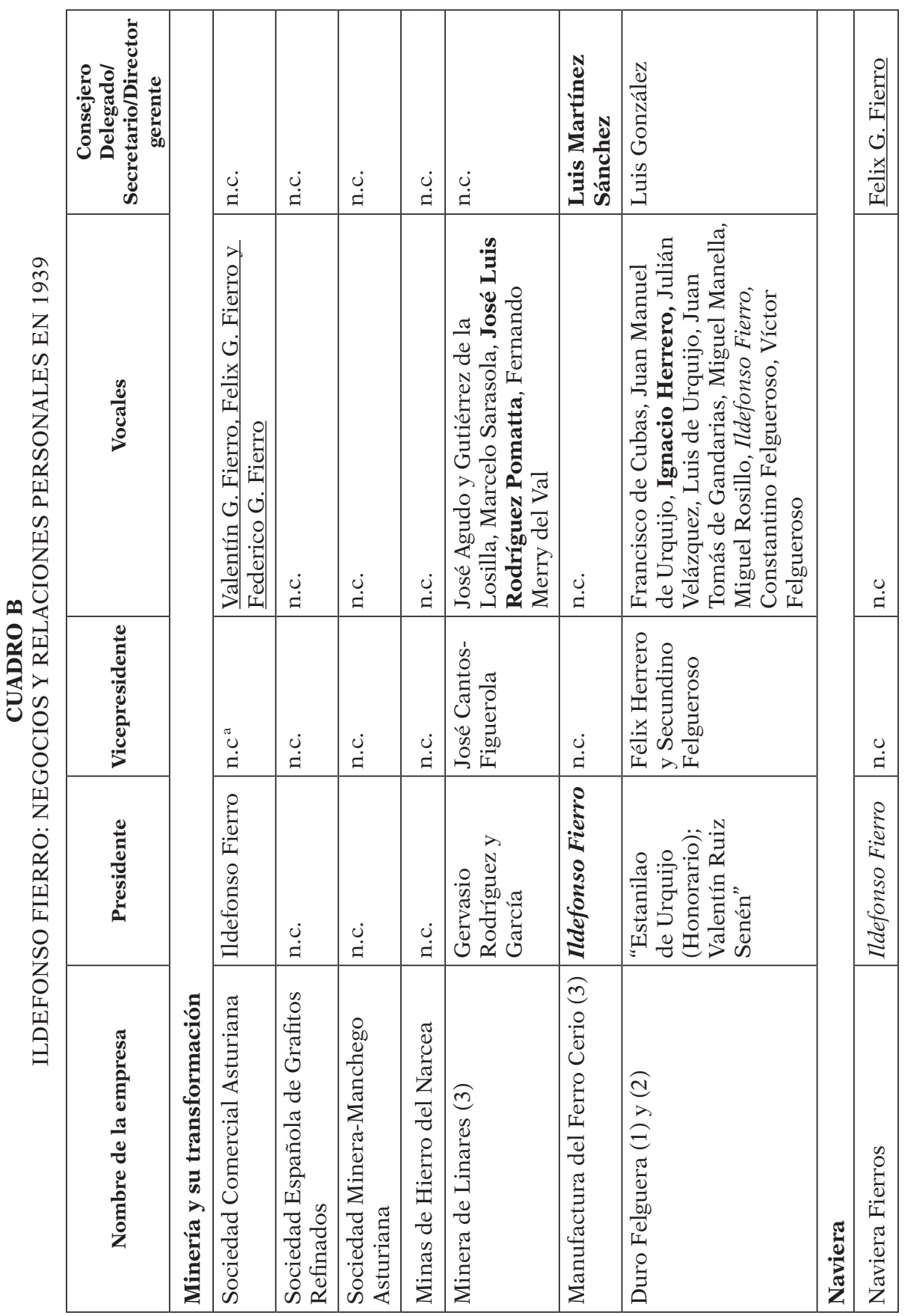




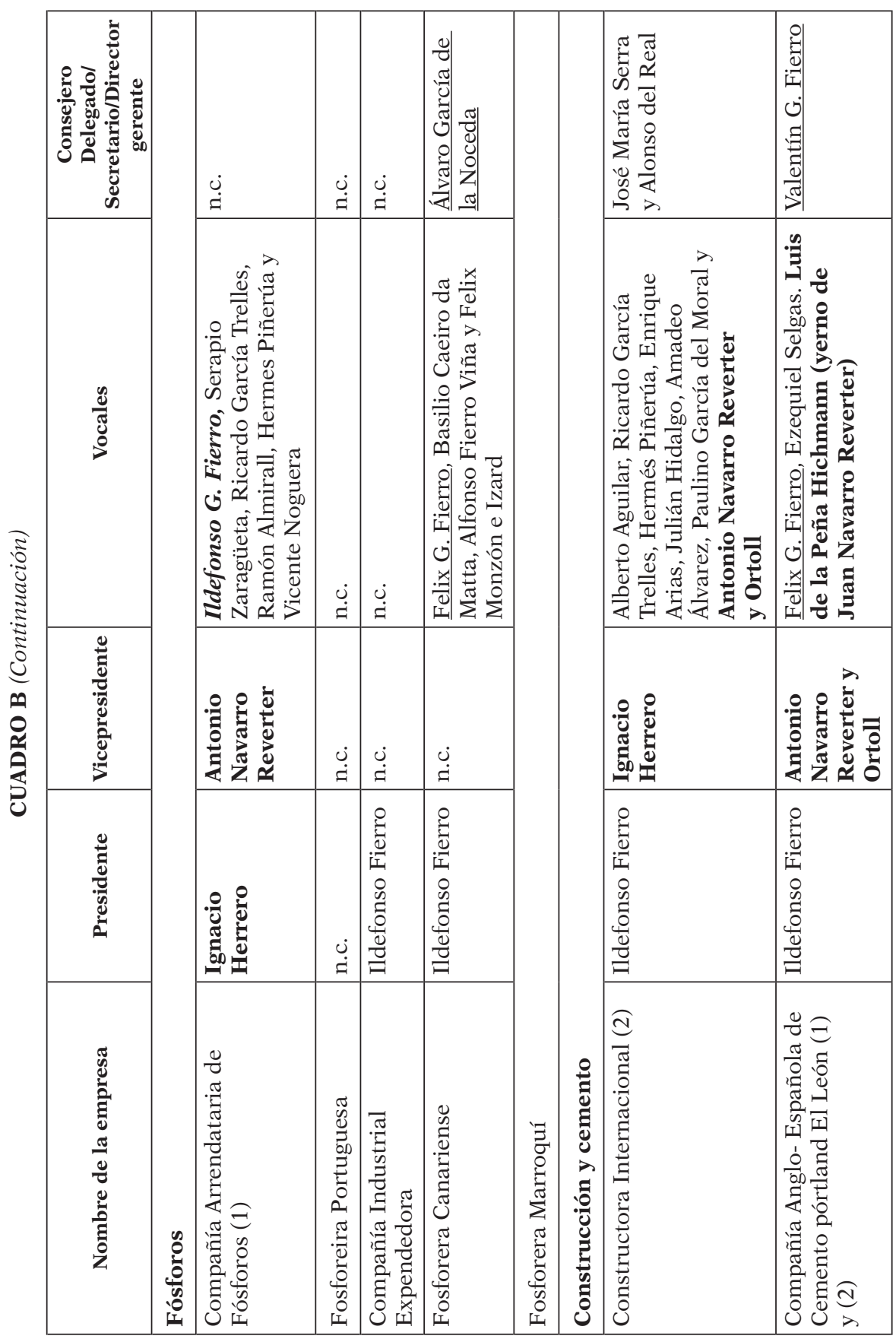




\begin{tabular}{|c|c|c|c|c|c|c|c|c|}
\hline 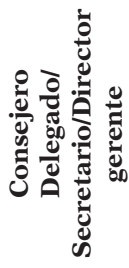 & & 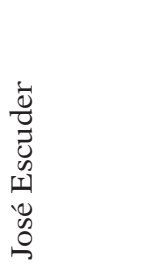 & 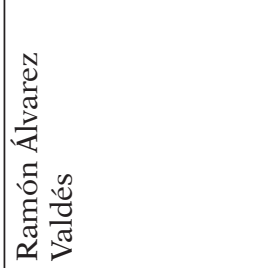 & 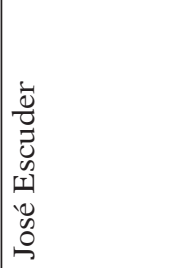 & & ن் & 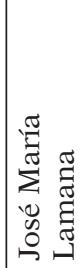 & 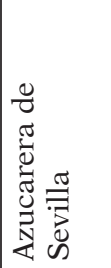 \\
\hline 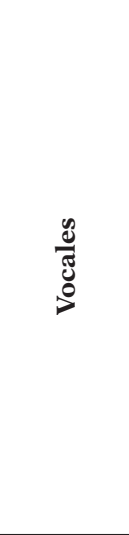 & & 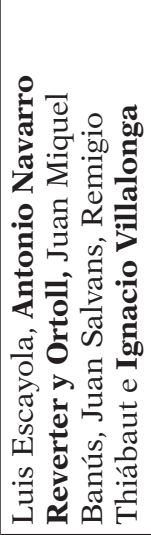 & 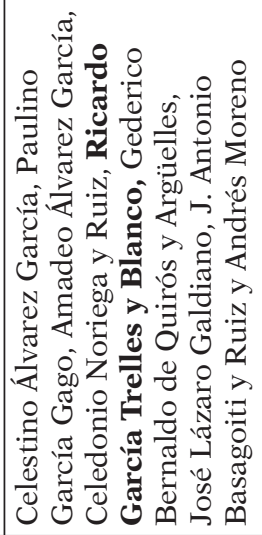 & 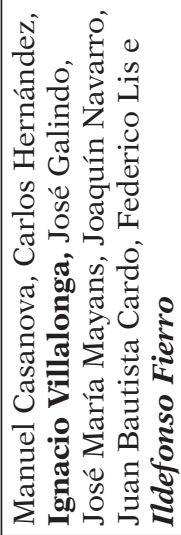 & & نُ & 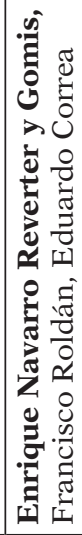 & 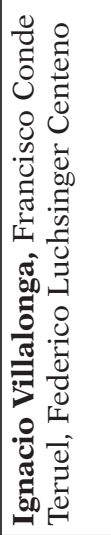 \\
\hline 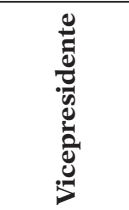 & & 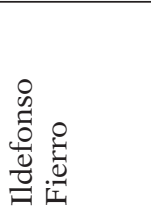 & 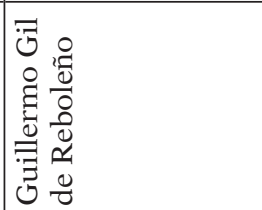 & $\begin{array}{ll}0 & \frac{\pi}{0} \\
0 & \frac{0}{0} \\
0 & 0 \\
5 & 0\end{array}$ & & نُ & 总 & 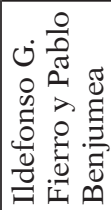 \\
\hline 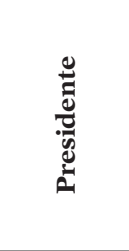 & & 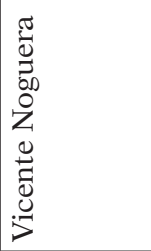 & 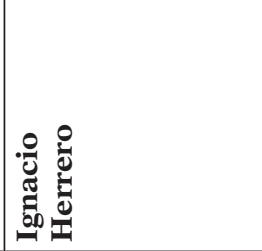 & 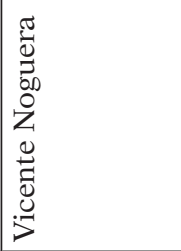 & & نُ & 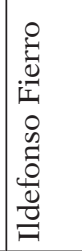 & 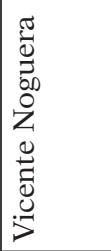 \\
\hline 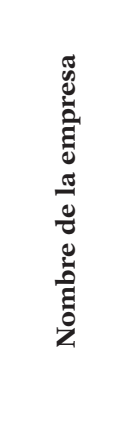 & 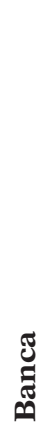 & 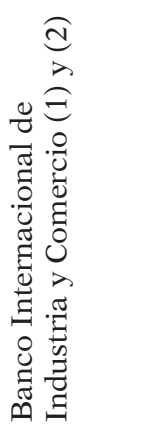 & 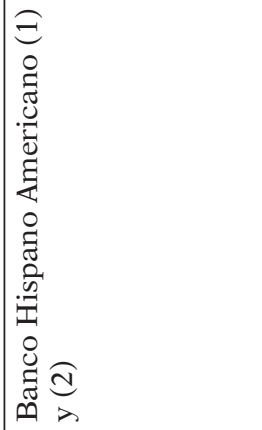 & 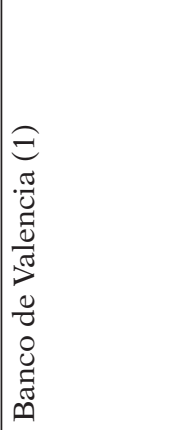 & $\stackrel{\mathscr{g}}{\tilde{\sigma}}$ & 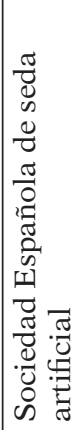 & 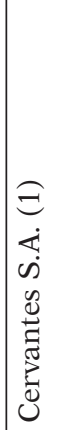 & 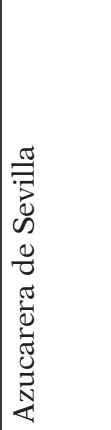 \\
\hline
\end{tabular}




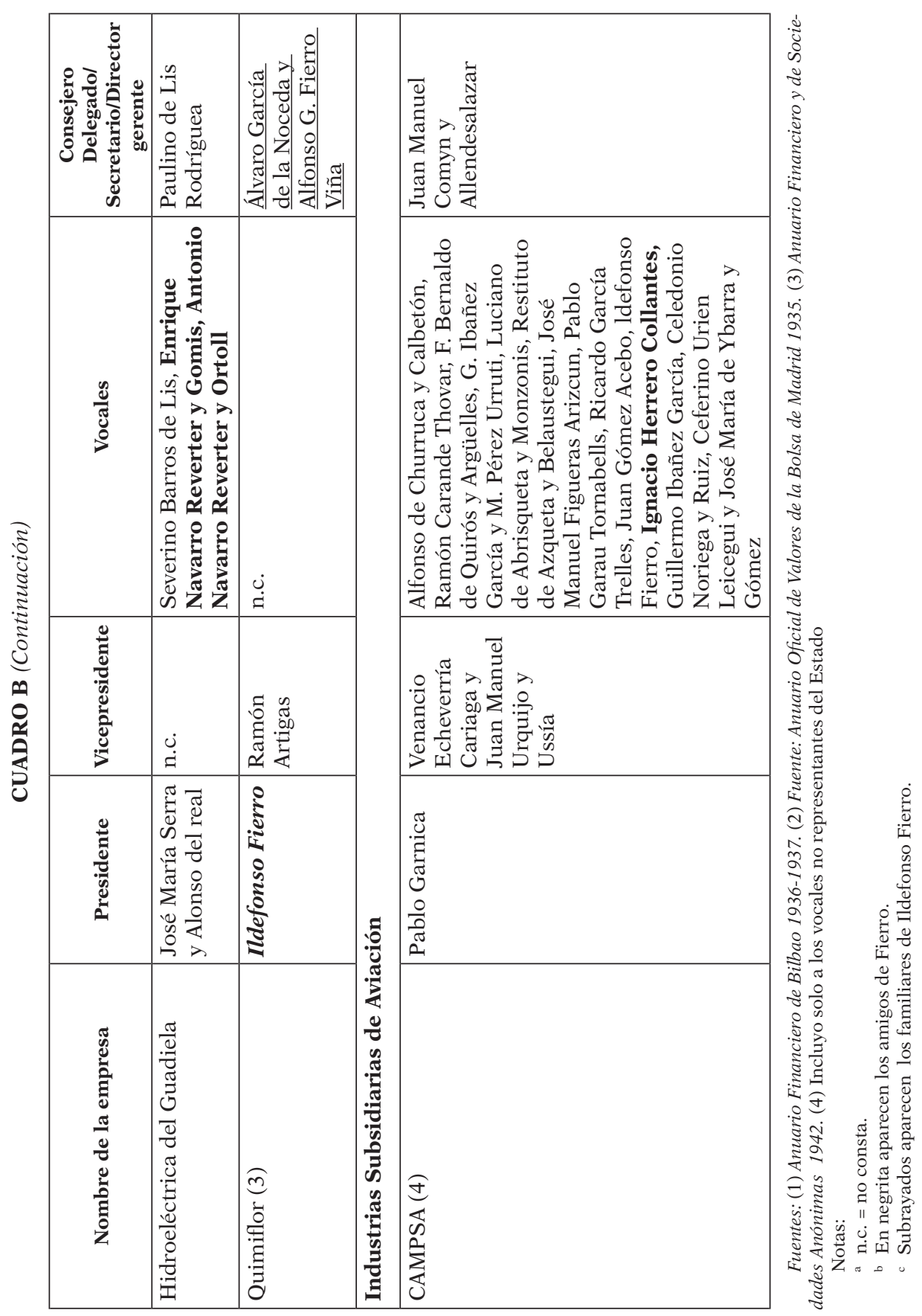

